\title{
Conservation and Convergence of Genetic Architecture in the Adaptive Radiation of Anolis lizards
}

4 Joel W. McGlothlin, ${ }^{1, *}$ Megan E. Kobiela, ${ }^{2}$ Helen V. Wright, ${ }^{3}$ Jason J. Kolbe, ${ }^{4}$ Jonathan B.

$5 \quad \operatorname{Losos},{ }^{5}$ and Edmund D. Brodie III $^{6}$

6

7 1. Department of Biological Sciences, Virginia Tech, Blacksburg, Virginia 24061; email:

$8 \quad$ joelmcg@vt.edu

9 2. School of Biological Sciences, University of Nebraska, Lincoln, Nebraska 68588; email:

$10 \quad$ mkobiela2@unl.edu

11 3. Computing Community Consortium, Computing Research Association, Washington, DC

12 20036; email: helenvwright2@gmail.com

13 4. Department of Biological Sciences, University of Rhode Island, Kingston, Rhode Island

14 02881; email: jjkolbe@uri.edu

15 5. Department of Biology, Washington University, Saint Louis, Missouri 63130; email:

$16 \quad 10 s o s @ w u s t l . e d u$

17 6. Department of Biology and Mountain Lake Biological Station, University of Virginia,

18 Charlottesville, Virginia 22904; email: edb9j@virginia.edu

$19{ }^{*}$ Corresponding author

20

21 Short running title: Conservation and Convergence of $\boldsymbol{G}$ 
22 ABSTRACT: The $\mathbf{G}$ matrix, which quantifies the genetic architecture of traits, is often viewed as an

23 evolutionary constraint. However, $\mathbf{G}$ can evolve in response to selection and may also be viewed

24 as a product of adaptive evolution. The evolution of similar $\mathbf{G}$ matrices in similar environments

25 would suggest that $\mathbf{G}$ evolves adaptively, but it is difficult to disentangle such effects from

26 phylogeny. Here, we use the adaptive radiation of Anolis lizards to ask whether convergence of $\mathbf{G}$

27 accompanies the repeated evolution of habitat specialists, or ecomorphs, across the Greater

28 Antilles. We measured $\mathbf{G}$ in seven species representing three ecomorphs (trunk-crown, trunk-

29 ground, and grass-bush). We found that the overall structure of $\mathbf{G}$ does not converge. Instead, the

30 structure of $\mathbf{G}$ is well conserved and displays a phylogenetic signal. However, several elements of

31 G showed signatures of convergence, indicating that some aspects of genetic architecture have

32 been shaped by selection. Most notably, genetic correlations between limb traits and body traits

33 were weaker in long-legged trunk-ground species, suggesting effects of recurrent selection on

34 limb length. Our results demonstrate that common selection pressures may have subtle but

35 consistent effects on the evolution of $\mathbf{G}$, even as the overall pattern of genetic architecture

36 remains conserved.

38 Keywords: adaptive radiation, Anolis lizards, constraint, G matrix, genetic correlation,

39 quantitative genetics 


\section{Introduction}

41 Genetic variation translates natural selection into evolutionary change (Falconer and MacKay

42 1996; Roff 1997). Understanding the nature of such genetic variation and the processes that shape

43 it has been a goal of evolutionary biology since the early days of population genetics

44 (Dobzhansky 1937). In evolutionary quantitative genetics, the pattern of genetic variation in a

45 population is described by the genetic variance-covariance matrix $\mathbf{G}$, which predicts the

46 multivariate response to phenotypic selection (Lande 1979). The $\mathbf{G}$ matrix can be used to make

47 accurate predictions of short-term evolutionary change (Grant and Grant 1995), but its utility for

48 making long-term predictions is more suspect because $\mathbf{G}$ itself may evolve during adaptive

49 evolution (Turelli 1988; Steppan et al. 2002). Although early theory argued for the stability of G

50 (Lande 1980), both more recent theoretical (Agrawal et al. 2001; Jones et al. 2003; 2004, 2012,

51 2014; Revell 2007; Arnold et al. 2008) and empirical results (Steppan et al. 2002; Cano et al.

52 2004; Doroszuk et al. 2008; Hine et al. 2009; Eroukhmanoff and Svensson 2011; Björklund et al.

53 2013; Careau et al. 2015) suggest that $\mathbf{G}$ can and does evolve, sometimes rapidly. Given enough

54 time, selection is expected to align $\mathbf{G}$ with the adaptive landscape (Cheverud 1984; Arnold et al.

55 2001, 2008; Jones et al. 2003, 2014; Revell 2007), potentially making $\mathbf{G}$ as much as a product of

56 adaptive evolution as a constraint upon it (Merilä and Björklund 2004).

57 Because stability and evolutionary lability of $\mathbf{G}$ are both plausible theoretical outcomes,

58 the relative importance of history and adaptation in shaping $\mathbf{G}$ is largely an empirical question

59 (Arnold et al. 2008). Several studies have shown a relationship between the shape of $\mathbf{G}$ and

60 divergence, suggesting the importance of genetic constraints in channeling evolutionary

61 outcomes (Bégin and Roff 2003; 2004; Blows and Hoffmann 2005; McGuigan et al. 2005; 
62 McGuigan 2006; Hansen and Houle 2008; Walsh and Blows 2009; Chenoweth et al. 2010;

63 Bolstad et al. 2014; Houle et al. 2017; McGlothlin et al. 2018; Walter et al. 2018). The early

64 stages of adaptive radiation are expected to be aligned with the "genetic line of least resistance"

65 describing the direction of greatest genetic variation within a population (Schluter 1996).

66 Although natural selection should be able to push phenotypes away from this line given enough

67 time, recent results suggest that evolutionary change may be predicted by axes of genetic

68 variation for tens of millions of years (Houle et al. 2017; McGlothlin et al. 2018). Conversely, it

69 is well established that both directional and nonlinear selection may alter aspects of G. For

70 example, correlational selection, which occurs when certain combinations of traits are favored

71 over others, can directly alter the strength of genetic correlations each generation (Phillips and

72 Arnold 1989; Jones et al. 2003; Revell 2007). Patterns of genetic correlation are often congruent

73 with axes of correlational selection in the wild (Brodie 1989; 1992; McGlothlin et al. 2005; Roff

74 and Fairbairn 2012), and genetic correlations can evolve in response to artificial correlational

75 selection (Delph et al. 2011; Steven et al. 2020).

Although comparative studies of $\mathbf{G}$ have become more common in recent years (Steppan

et al. 2002; Bégin and Roff 2003; Hine et al. 2009; Eroukhmanoff and Svensson 2011; Walter et

al. 2018), none have been able to disentangle the effects of shared ancestry from similar selection

79 pressures in determining the evolution of $\mathbf{G}$. Convergent evolution of $\mathbf{G}$ or its elements in similar

80 environments would provide strong evidence that changes in $\mathbf{G}$ represent adaptation of genetic

81 architecture (Losos 2011). The adaptive radiation of West Indian Anolis lizards provides an ideal

82 testing ground for hypotheses about the evolution of $\mathbf{G}$ because the effects of phylogenetic

83 history and ecological selection are largely decoupled (Losos 1994; 2009; 2011). In the Greater

84 Antilles, anoles have diversified into 120 species, 95 of which can be classified as one of six 
85 habitat specialists, or ecomorphs, each of which has evolved multiple times throughout the Anolis

86 radiation (Williams 1972; Losos et al. 1998; Beuttell and Losos 1999; Losos 2009). Species with

87 dissimilar morphology on the same island tend to be more closely related than are those with

88 similar morphology on different islands, indicating that the characteristic morphology of

89 ecomorphs is due to convergent evolution (Losos et al. 1998; Harmon et al. 2005; Mahler et al.

90 2013). This repeated adaptive radiation leads to explicit predictions for the evolution of $\mathbf{G}$. If $\mathbf{G}$

91 responds predictably to similar selection pressures, $\mathbf{G}$ should show signatures of convergence

92 among the independent origins of the same ecomorph. Conversely, if $\mathbf{G}$ evolves relatively slowly

93 and does not respond predictably to similar selection pressures, $\mathbf{G}$ or its elements should be more

94 similar within lineages than within ecomorph classes.

95 Previous work in Anolis using phenotypic variance-covariance matrices (P) as proxies for

$96 \mathbf{G}$ (Cheverud 1988) suggests that selection may indeed lead to convergence in (co)variance

97 structure. A study comparing $\mathbf{P}$ in eight Anolis species showed significant variation in covariance

98 structure across the radiation and demonstrated convergent changes in $\mathbf{P}$ in three distantly related

99 species from the same ecomorph class (Kolbe et al. 2011). In a separate study, P showed

100 significant alignment with the matrix of nonlinear selection $(\gamma)$ in $A$. cristatellus, suggesting that

101 contemporary stabilizing and correlational selection may act to shape the pattern of phenotypic

102 (co)variance within species (Revell et al. 2010). These results suggest that selection plays a role

103 in shaping genetic architecture in anoles, but patterns of phenotypic covariance do not necessarily

104 mirror patterns of genetic covariance (Hadfield et al. 2007). Thus, comparative studies that

105 directly estimate $\mathbf{G}$ are necessary to test whether its structure is more influenced by phylogenetic

106 history or convergent evolution. 
In this study, we compare $\mathbf{G}$ matrices in seven Anolis species reared in a controlled laboratory environment. We chose species from lineages originating on three different islands,

109 Puerto Rico, Jamaica, and Cuba, and included three ecomorphs, trunk-crown (three species),

110 trunk-ground (three species), and grass-bush (one species), which are distinguished by their

111 habitat use, coloration, and skeletal morphology (Williams 1972; Beuttell and Losos 1999;

112 Harmon et al. 2005; Losos 2009). Trunk-crown lizards are typically found high in trees and are

113 usually green with relatively short legs for climbing and clinging to narrow perches. Trunk-

114 ground lizards tend to be found on low perches or on the ground and are typically brown with

115 long hindlimbs that aid in running quickly and jumping far (Losos and Sinervo 1989; Losos

116 1990; Irschick and Losos 1998; Beuttell and Losos 1999). The third ecomorph, grass-bush, has a

117 slender body that matches its narrow perches and long hindlimbs that allow it to both run and

118 jump well (Losos 1990; Beuttell and Losos 1999). The three trunk-crown species are distantly

119 related to one another, as are the trunk-ground species. Both ecomorphs may have evolved three

120 separate times, although it cannot be ruled out that one of these ecomorphs represents the

121 ancestral state for the anole radiation (Losos 2009). Because of the importance of skeletal

122 morphology, and limb length in particular, to the evolution of these ecomorphs, our estimates of

$123 \mathbf{G}$ focus on skeletal traits.

124 Our previous results have shown that $\mathbf{G}$ varies substantially across these Anolis species,

125 while retaining conserved axes of genetic variation (McGlothlin et al. 2018). Specifically, G

126 matrices varied most in size (overall genetic variance), and the major axis of genetic variance

127 remained similar in orientation across all species. This major axis of genetic variance was similar

128 in orientation to the major axis of morphological divergence, suggesting that divergence has

129 occurred along a genetic line of least resistance even though $\mathbf{G}$ has not remained constant. The 
130 largest evolutionary changes in $\mathbf{G}$ were also aligned with the major axes of both genetic variance

131 and morphological divergence. This triple alignment may have been caused by deep genetic

132 constraints underlying both the evolution of $\mathbf{G}$ and morphological divergence, alignment of $\mathbf{G}$

133 with the adaptive landscape, genetic drift, or some combination of the three (McGlothlin et al.

134 2018).

135 Here, we explicitly consider the role of selection in shaping G-matrix evolution across the

136 Anolis radiation by testing whether aspects of $\mathbf{G}$ show patterns of convergence that mirror the

137 repeated evolution of ecomorphs. To do so, we use two types of comparisons. First, we test for

138 convergence of the overall structure of $\mathbf{G}$ by asking whether random skewers correlations, which

139 are estimates of pairwise similarity in the predicted multivariate response to selection, are better

140 predicted by shared evolutionary history or shared ecology. Second, we conduct similar tests for

141 individual elements of $\mathbf{G}$ (i.e., variances and covariances of individual traits) to test for signatures

142 of convergence on a finer scale. Although many processes, including both selection and drift,

143 could lead to similarities in $\mathbf{G}$ among more closely related species, convergence in the structure

144 of $\mathbf{G}$ among distantly related species of the same ecomorph would provide strong evidence that $\mathbf{G}$

145 may be predictably shaped by common selection pressures.

Methods

\section{Estimation of $\boldsymbol{G}$}

150 Detailed methods for estimation of the $\mathbf{G}$ matrices used here are reported elsewhere (McGlothlin

151 et al. 2018). Briefly, adults from seven Anolis species, representing independent origins of trunk- 
152 crown (A. evermanni, Puerto Rico; A. grahami, Jamaica; A. smaragdinus, a Bahamian species

153 descended from $A$. porcatus on Cuba), trunk-ground (A. cristatellus, Puerto Rico; A. lineatopus,

154 Jamaica; A. sagrei, Cuba), and grass-bush ecomorphs (A. pulchellus, Puerto Rico), were collected

155 from the wild (Fig. 1). Due to travel restrictions, species from Cuban lineages were collected

156 from South Bimini, The Bahamas, where they occur naturally. These seven species shared a

157 common ancestor approximately 41.5-43.5 million years ago, and the most recent phylogenetic

158 split (between A. cristatellus and A. pulchellus) dates is estimated at 19.8-22.5 million years ago

159 (fig. 1, Zheng and Wiens 2016; Poe et al. 2017).

Adults were housed in individual cages in the laboratory except when paired for breeding

161 and held at controlled photoperiod (12L:12D for Puerto Rican and Jamaican adults and 13L:11D

162 for Bahamian adults), temperature $\left(28^{\circ} \mathrm{C}\right.$ during the day and $25^{\circ} \mathrm{C}$ at night $)$, and relative humidity

163 (65\%). Lizards were provided with a perch, a mesh hammock for basking near an adjacent UVB

164 bulb, and a carpet substrate. Adults were mated in a paternal half-sib breeding design (average of

16547 sires and 69 dams per species) to produce offspring (2,904 total, see McGlothlin et al. 2018

166 for more sampling details). Laying females were provided with potted plants, which were

167 checked weekly for eggs, which were placed in individual cups with a 1:1 mixture of water and

168 vermiculite and held in an incubator at $28^{\circ} \mathrm{C}$ and $80 \%$ humidity until hatching.

169 Juveniles were reared in individual cages until 6 months of age and were provided with

170 crickets and water daily. At $0,1,3$, and 6 months of age, we X-rayed juveniles by chilling them

171 for $10 \mathrm{~min}$ at $5^{\circ} \mathrm{C}$ in small plastic bags. The bags were then secured with masking tape to a film

172 cartridge (Kodak Biomax XAR) for imaging in a Faxitron 43805N radiography system.

173 Developed radiographs were digitized using a flatbed scanner. Using ImageJ (NIH), we measured

174 snout-vent length (SVL) and eight other skeletal traits, jaw length (JL), head width (HW), 
175 pectoral width (PECT), pelvis width (PELV), humerus (HUM), ulna (UL), femur (FEM), and

176 tibia (TIB; see Fig. 1A for location of measured traits). In all, 9,369 individual X-ray images

177 were measured (McGlothlin et al. 2018). We used multivariate repeated measures animal models

178 in ASReml 3.0 (Gilmour et al. 2009) to estimate $\mathbf{G}$ matrices for natural-log transformed traits,

179 with size (natural-log SVL) as a covariate to correct for age and growth. These models included

180 two random animal effects, one linked to the pedigree to estimate additive genetic (co)variance

181 and a second unlinked effect to estimate effects of permanent environment. All species could not

182 be reliably sexed as juveniles; therefore, we did not correct for sex in our models. In one species

183 that has been studied extensively in the laboratory, A. sagrei, sexual size dimorphism is not

184 noticeable at hatching and only becomes elaborated after 6 months of age with the maturation of

185 testes in males (Cox et al. 2017). Genetic correlations are shown (along with heritabilities) in

186 table A1 and visualized in fig. 1; full G matrices, reprinted from McGlothlin et al. (2018), are

187 also shown in table A1. Permanent environment (co)variances, which were generally at least an

188 order of magnitude smaller than genetic (co)variances, and residual (co)variances are not

189 presented here but were used in the calculation of total phenotypic variance for calculating

190 heritabilities. As reported previously, in all but two species, all eight traits we measured were

191 significantly heritable (mean $h^{2}$ across species \pm s.d.: JL, $.40 \pm .150 ; \mathrm{HW}, .22 \pm .084 ;$ PECT, .21

$192 \pm .073 ;$ PELV, .22 $\pm .046 ;$ HUM, .16 $\pm .047 ;$ UL, .15 $\pm .042 ;$ FEM, $.45 \pm .143$, TIB, $.54 \pm .091$

193 table A1; McGlothlin et al. 2018). In general, genetic correlations were strong and positive for

194 pairs of limb traits and both weaker and more variable across species for other trait combinations

195 (fig. 1, table A1; McGlothlin et al. 2018). 


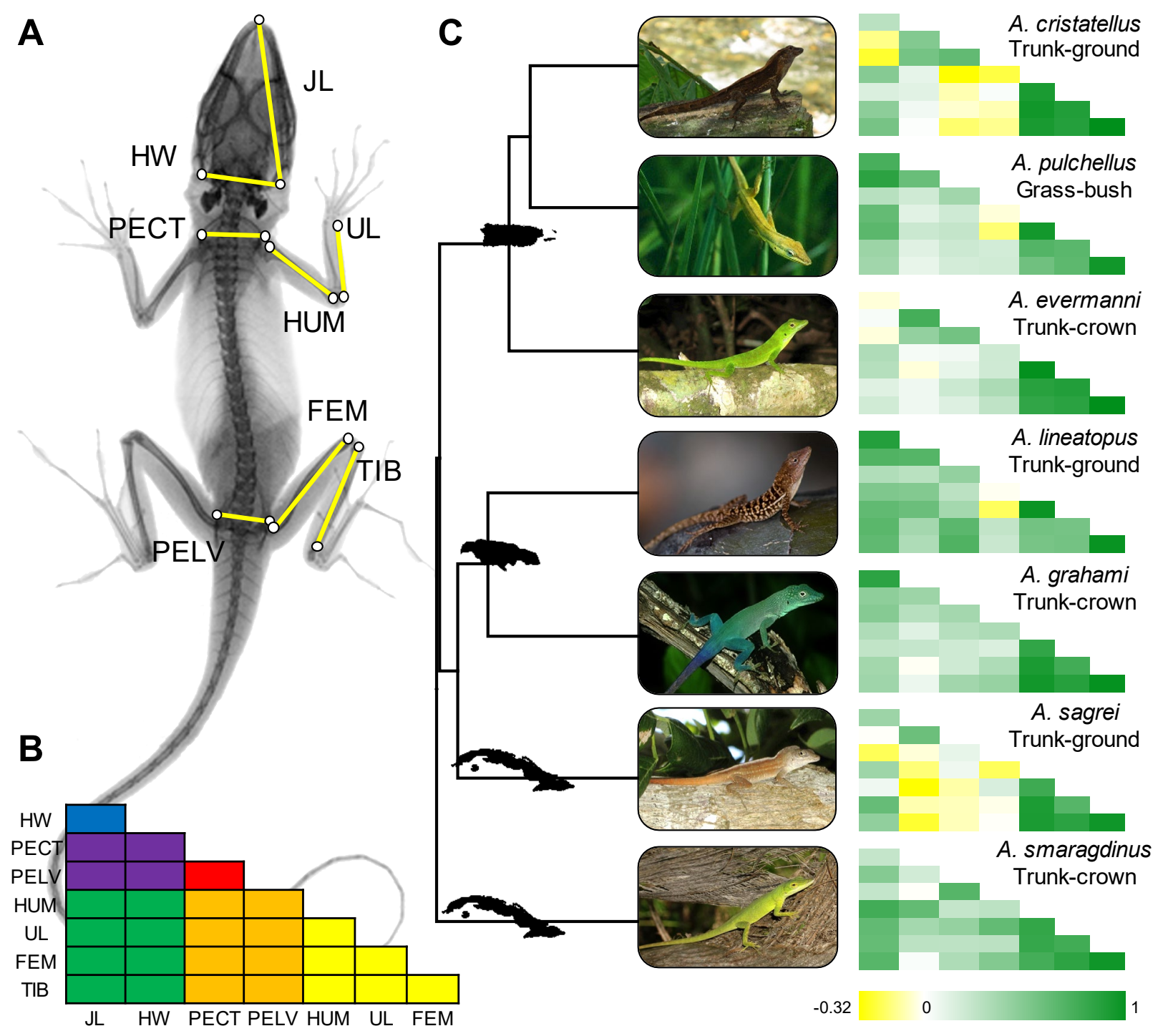

Figure 1: $(A)$ Traits measured in this study: $\mathrm{JL}=$ jaw length, $\mathrm{HW}=$ head width, $\mathrm{PECT}=$ pectoral width, PELV = pelvis width, HUM = humerus, UL = ulna, FEM = femur, TIB = tibia. $(B)$ Schematic of a genetic correlation matrix showing the location of each trait. Elements are colorcoded based on morphological modules (head, body, and limbs; see Methods), showing withinmodule correlations in primary colors (blue $=$ head, $\mathrm{red}=$ body, yellow $=$ limbs) and between module correlations in secondary colors (violet $=$ head-body, green $=$ head-limb, orange $=$ bodylimb). (C) Graphical representation of genetic correlation matrices for each species. Positive correlations are shown in green and negative correlations are shown in yellow, with brighter colors signifying stronger correlations. See table A1 for values. Photographs by J.B.L. ( $A$. pulchellus, A. lineatopus, and A. grahami), and E.D.B. III (all other species). 


\section{Statistical Analyses}

197 All statistical analyses using G matrices were performed in R 3.5.3 (R Core Team 2019). To

198 incorporate estimation error in $\mathbf{G}$ into our analyses, we used the restricted maximum-likelihood

199 multivariate normal (REML-MVN) method developed by Houle and Meyer (2015). We used

200 point estimates of $\mathbf{G}$ and the sampling (co)variance matrix of (co)variance components, which is

201 calculated by ASReml as the inverse of the average information matrix (Gilmour et al. 2009), to

202 define a multivariate normal distribution. From this distribution, we generated 10,000 samples of

$203 \mathbf{G}$ for each species using the function rmvn from the R package mgcv (Wood 2012). All further

204 analyses were run using both the point estimates of $\mathbf{G}$, from which we estimated parameters and

205 test statistics, and the set of 10,000 REML-MVN samples per species, from which we calculated

$20695 \%$ confidence intervals using the $2.5 \%$ and $97.5 \%$ quantiles from the parameter distribution. A

207 parameter was considered to be statistically supported when its $95 \%$ confidence interval did not

208 overlap the expected null value (often zero). We clarify the specific ways REML-MVN samples

209 were used for each analysis below.

210 To quantify pairwise similarity in the overall structure of $\mathbf{G}$, we used random skewers

211 analysis, which compares the response to selection predicted by a pair of $\mathbf{G}$ matrices (Marroig

212 and Cheverud 2001; Cheverud and Marroig 2007; Revell 2007; Aguirre et al. 2014). Random

213 skewers analysis has the advantage of providing an evolutionarily relevant comparison of $\mathbf{G}$

214 using a single metric. We used the function RandomSkewers in the R package evolQG (Melo et

215 al. 2015) to apply 10,000 random selection gradients $(\boldsymbol{\beta})$ to all seven $\mathbf{G}$ matrices. Each element of

216 these skewers was drawn from a normal distribution, after which each skewer was normalized to

217 unit length and used to calculate the predicted multivariate selection response $(\Delta \overline{\mathbf{z}})$ from the 
218 multivariate breeder's equation, $\Delta \overline{\mathbf{z}}=\mathbf{G} \boldsymbol{\beta}$ (Lande 1979). The correlation in response to selection

219 for two species, or the random skewers correlation $\left(r_{\mathrm{RS}}\right)$, was calculated as the pairwise vector

220 correlation of the resultant 10,000 estimates of $\Delta \overline{\mathbf{z}}$. To incorporate estimation error, $r_{\mathrm{RS}}$ was

221 recalculated for 10,000 sets of seven $\mathbf{G}$ matrices each using our REML-MVN samples. We report

222 the mean and 95\% confidence intervals of this distribution in addition to our point estimate.

223 Incorporating error pairs of $\mathbf{G}$ matrices leads to negatively skewed distributions of the REML-

224 MVN estimates of $r_{\mathrm{RS}}$. Thus, means of the REML-MVN estimates of $r_{\mathrm{RS}}$ tend to be lower than

225 the point estimates.

226 To determine whether more closely related species had more similar $\mathbf{G}$ matrices, we used

227 a Mantel test to compare a matrix of $r_{\mathrm{RS}}$ to a patristic distance matrix, which was calculated using

228 a tree pruned from a dated squamate phylogeny (Zheng and Wiens 2016); dates from a tree of all

229 Anolis species (Poe et al. 2017), which had identical topology for our species, were similar.

230 Although Mantel tests are not useful for comparing (co)variance matrices directly (Steppan et al.

231 2002) and are not recommended for use in the phylogenetic comparative method when they can

232 be avoided, they are the only option when comparative analyses involve data that can only be

233 expressed as either a correlation or a distance between species (Harmon and Glor 2010). A

234 negative Mantel correlation $\left(r_{\mathrm{M}}<0\right)$ between $r_{\mathrm{RS}}$ and patristic distance would indicate that the

235 similarity in the structure of $\mathbf{G}$ is explained by phylogentic similarity. To determine whether

236 unrelated species of the same ecomorph displayed convergence in the structure of $\mathbf{G}$, we

237 generated a matrix consisting of zeros (different ecomorph) and ones (same ecomorph) and

238 compared it to a matrix of $r_{\mathrm{RS}}$ using a partial Mantel test that used the patristic distance matrix as

239 the control matrix. The single grass-bush species, $A$. pulchellus, was excluded from this and all 
240 other analyses that included an ecomorph effect. A positive correlation $\left(r_{\mathrm{M}}<0\right)$ between the $r_{\mathrm{RS}}$

241 matrix and the ecomorph matrix would indicate convergence.

242 Mantel correlations were calculated in R using the base function corr (simple Mantel test)

243 or the function pcor (partial Mantel test) from the package ppcor (Kim 2015). We did not perform

244 permutation tests to assess statistical significance as is the typical practice when performing

245 Mantel tests. Rather, we conducted separate Mantel tests for each of 10,000 sets of $r_{\mathrm{RS}}$ matrices

246 calculated using our REML-MVN samples and report the mean and 95\% confidence intervals of

247 this distribution.

248 Evolutionary patterns in $\mathbf{G}$ may involve changes that are subtler than can be detected in

249 analyses of its overall structure. Therefore, we also tested for the effects of shared evolutionary

250 history and shared ecology on the individual elements of $\mathbf{G}$. We compared genetic variances

251 (diagonal elements of $\mathbf{G}$ ) and genetic correlations (off-diagonal elements of $\mathbf{G}$ standardized by

252 the square root of the product of the variances) across $\mathbf{G}$ matrices, testing for both phylogenetic

253 signal and differences between ecomorphs (trunk-crown vs. trunk-ground). We present

254 comparisons of genetic correlations rather than genetic covariances so that tests for associations

255 between traits would be independent of differences in variance across species. However, we note

256 that analyses using covariances gave nearly identical results (not shown).

257 To test for the effects of shared evolutionary history, we used Blomberg's $K$ as an

258 estimate of phylogenetic signal (Blomberg et al. 2003; implented in the R package phytools,

259 Revell 2012). Values of $K=1$ indicate phylogenetic signal consistent with a Brownian motion

260 model of evolution. Values of $K<1$ indicate weaker phylogenetic signal, and $K>1$ indicate

261 stronger signal than would be predicted from a Brownian motion model. We tested for effects of

262 shared ecology on genetic variance and genetic correlations using phylogenetic generalized least 
263 squares (Martins and Hansen 1997) with ecomorph as a predictor (coding trunk-crown as 0 and

264 trunk-ground as 1; A.pulchellus was excluded), our dated tree, and an assumption of Brownian

265 motion evolution (implemented in the R package APE, Paradis et al. 2004). Alternative models

266 that assumed an Ornstein-Uhlenbeck evolutionary model provided similar results (not shown).

267 For each test, we report the evolutionary correlation $\left(r_{\mathrm{e}}\right)$ between the element of $\mathbf{G}$ and ecomorph

268 to remove effects of scale. For a given element of $\mathbf{G}, r_{\mathrm{e}}>0$ indicates a larger value for trunk-

269 ground species, and $r_{\mathrm{e}}<0$ indicates a larger value for trunk-crown species. Both of these analyses

270 were conducted for both our point estimates and our REML-MVN samples to incorporate

271 estimation error. Using the 95\% confidence intervals from the distributions of REML-MVN

272 estimates, we note deviations from both $K=0$ and $K=1$ for phylogenetic signal and $r_{\mathrm{e}}=0$ for the

273 evolutionary correlation.

274 For visualization, we grouped our estimates of phylogenetic signal and evolutionary

275 correlation into six groups based on phenotypic module. Three groups consisted of elements of $\mathbf{G}$

276 within modules, head (JW, HL), body (PECT, PELV), and limbs (HUM, UL, FEM, and TIB),

277 and three contained elements of $\mathbf{G}$ between modules, head-limb, head-body, and body-limb.

\section{Results}

\section{Overall Structure of $\boldsymbol{G}$}

282 Predicted responses to selection were highly correlated between all pairs of species $\left(\mathrm{mean} r_{\mathrm{RS}}=\right.$

283.84 , range $.75-.92$, REML-MVN mean $r_{\mathrm{RS}}=0.73$, range $0.61-0.86$; table A2, fig. 2 ),

284 suggesting that the species have $\mathbf{G}$ matrices with similar overall structure despite being separated 
285 for 20-44 million years. G-matrix similarity was negatively correlated with phylogenetic distance

$286\left(r_{\mathrm{M}}=-.44\right.$; REML-MVN estimate: $\left.r_{\mathrm{M}}[95 \% \mathrm{CI}]=-.41[-.59,-.15]\right)$, indicating that closely related

287 species have $\mathbf{G}$ matrices that predict a more similar evolutionary resposne. More distantly related

288 pairs of species also displayed more variable values of $r_{\mathrm{RS}}$, with some distantly related pairs of

289 species showing highly similar $\mathbf{G}$ matrices and others showing highly dissimilar G (fig. 2).

290 Overall similarity of $\mathbf{G}$ was not predicted by ecomorph $\left(r_{\mathrm{M}}=-.12\right.$; REML-MVN estimate: $r_{\mathrm{M}}$

$291[95 \% \mathrm{CI}]=.04[-.22, .32])$. However, the two distantly related trunk-ground species $A$.

292 cristatellus and A. sagrei did have highly similar G matrices (figs. 2 \& 3).

\section{Individual Elements of $\boldsymbol{G}$}

295 All individual elements of $\mathbf{G}$ showed phylogenetic signal significantly higher than $K=0$ but

296 indistinguishable from $K=1$, which is the null expectation of the Brownian motion model (mean

$297 K=.91$, REML-MVN mean $K=.94$; fig. 4A, table A3). Phylogenetic signal did not exhibit any

298 detectable patterns across trait groups (fig. 4A).

299 Six elements of $\mathbf{G}$ differed significantly between trunk-crown and trunk-ground

300 ecomorphs. Specifically, genetic correlations between pelvis width and both jaw length and all

301 four limb bones were significantly lower in trunk-ground species than in trunk-crown species

302 (fig. 4B; table A4). In addition, genetic correlations between jaw length and femur length were

303 higher in trunk-ground species than in trunk-crown species (fig. 4B; table A4). In some cases,

304 these effects involved changes in the sign of genetic correlations from positive in trunk-crown

305 species to negative in trunk-ground species (fig. 1). Although not a statistically significant effect,

306 genetic correlations both among limb bones and between pectoral width and all four limb bones 


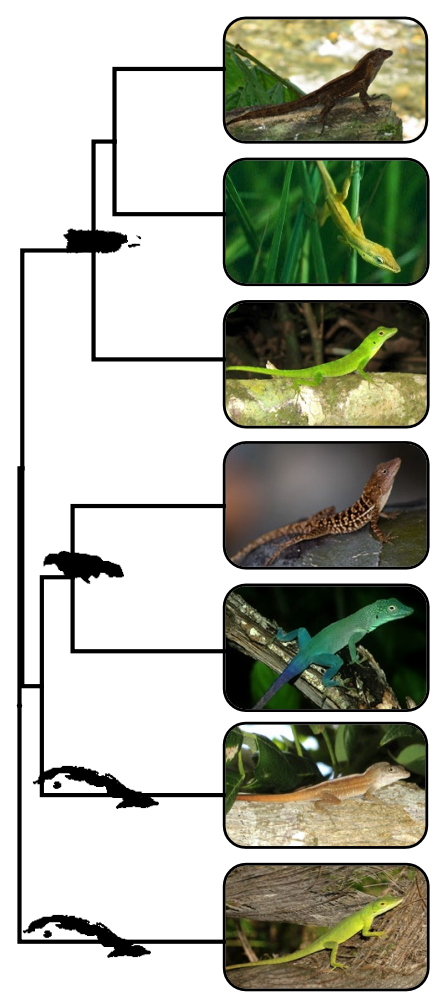

\section{A. cristatellus}

Trunk-ground

A. pulchellus

Grass-bush

A. evermanni

Trunk-crown

A. lineatopus

Trunk-ground

A. grahami

Trunk-crown

A. sagrei

Trunk-ground

A. smaragdinus

Trunk-crown
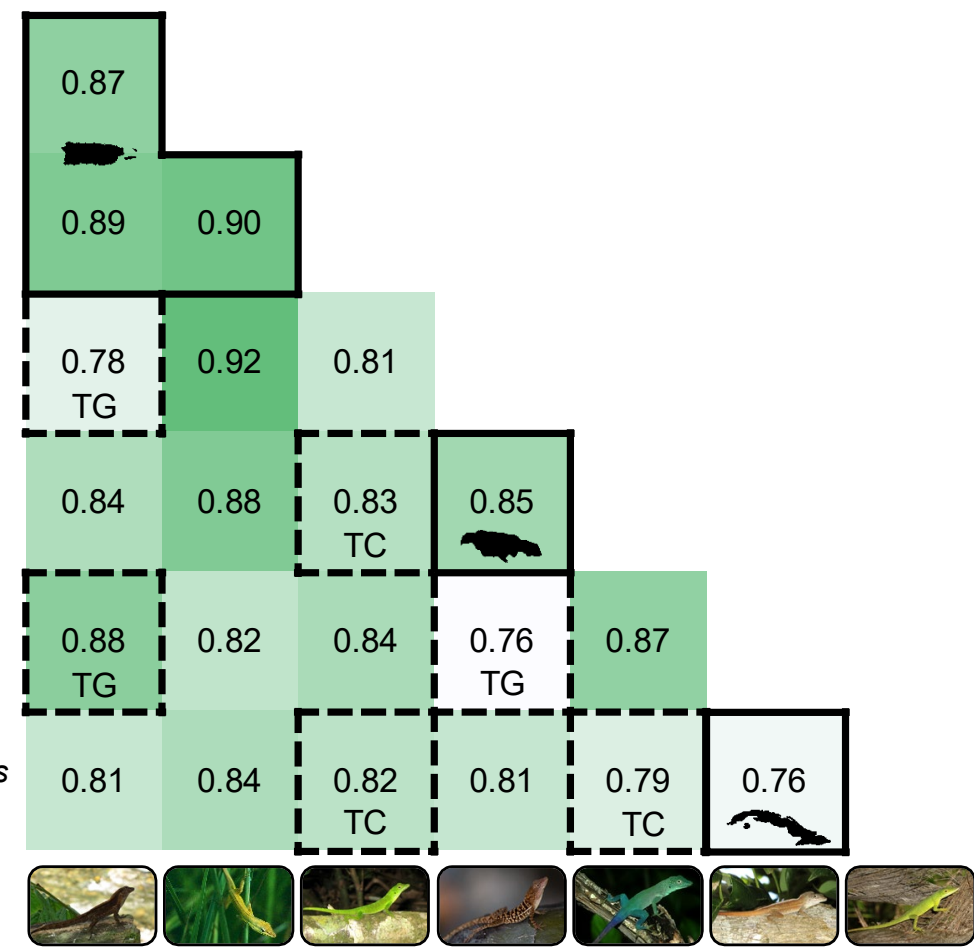

Figure 2: Correlations between species in the overall structure of the $\mathbf{G}$ matrix as measured via random skewers correlations $\left(r_{\mathrm{RS}}\right)$. Stronger correlations are represented by darker shading. Within-island comparisons are shown with a solid border, and within-ecomorph comparisons are shown with a dashed border $(\mathrm{TC}=$ trunk-crown, $\mathrm{TG}=$ trunk-ground). Islands of origin are represented by their shapes on the phylogeny (Puerto Rico, Jamaica, and Cuba, from top to bottom) and for the three within-island comparisons. Note that despite originating on Cuba, $A$. sagrei is actually more closely related to Jamaican species than to A. smaragdinus. The phylogeny is pruned from a dated tree of squamates (Zheng and Wiens 2016). 


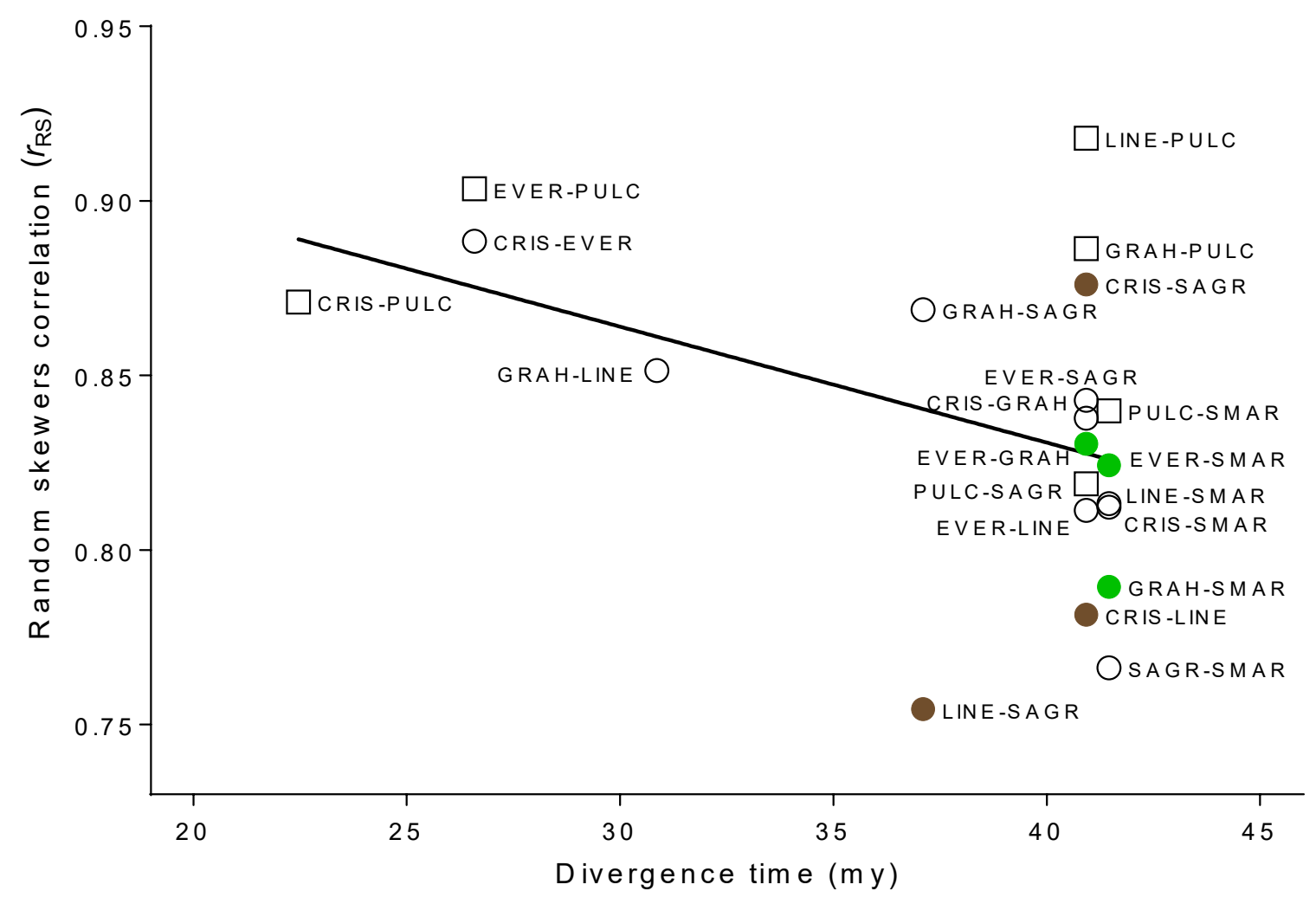

Figure 3: Relationship between divergence time (millions of years, my) and random skewers correlations $\left(r_{\mathrm{RS}}\right)$. G matrices of more distantly related species are significantly less similar and more variable in $r_{\mathrm{RS}}$. Within-ecomorph comparisons are shown as colored circles (green $=$ trunkcrown and brown = trunk-ground), with trunk-crown/trunk-ground comparisons as open circles and comparisons with the grass-bush species as open squares. Each point is labeled with four letter codes for the two species under comparison (CRIS $=$ A. cristatellus, $\mathrm{EVER}=A$. evermanni, $\mathrm{GRAH}=A$. grahami, $\mathrm{LINE}=A$. lineatopus, $\mathrm{PULC}=A$. pulchellus, $\mathrm{SAGR}=A$. sagrei, $\mathrm{SMAR}=$ A. smaragdinus). A line of best fit from a least-squares regression is added for visualization. 


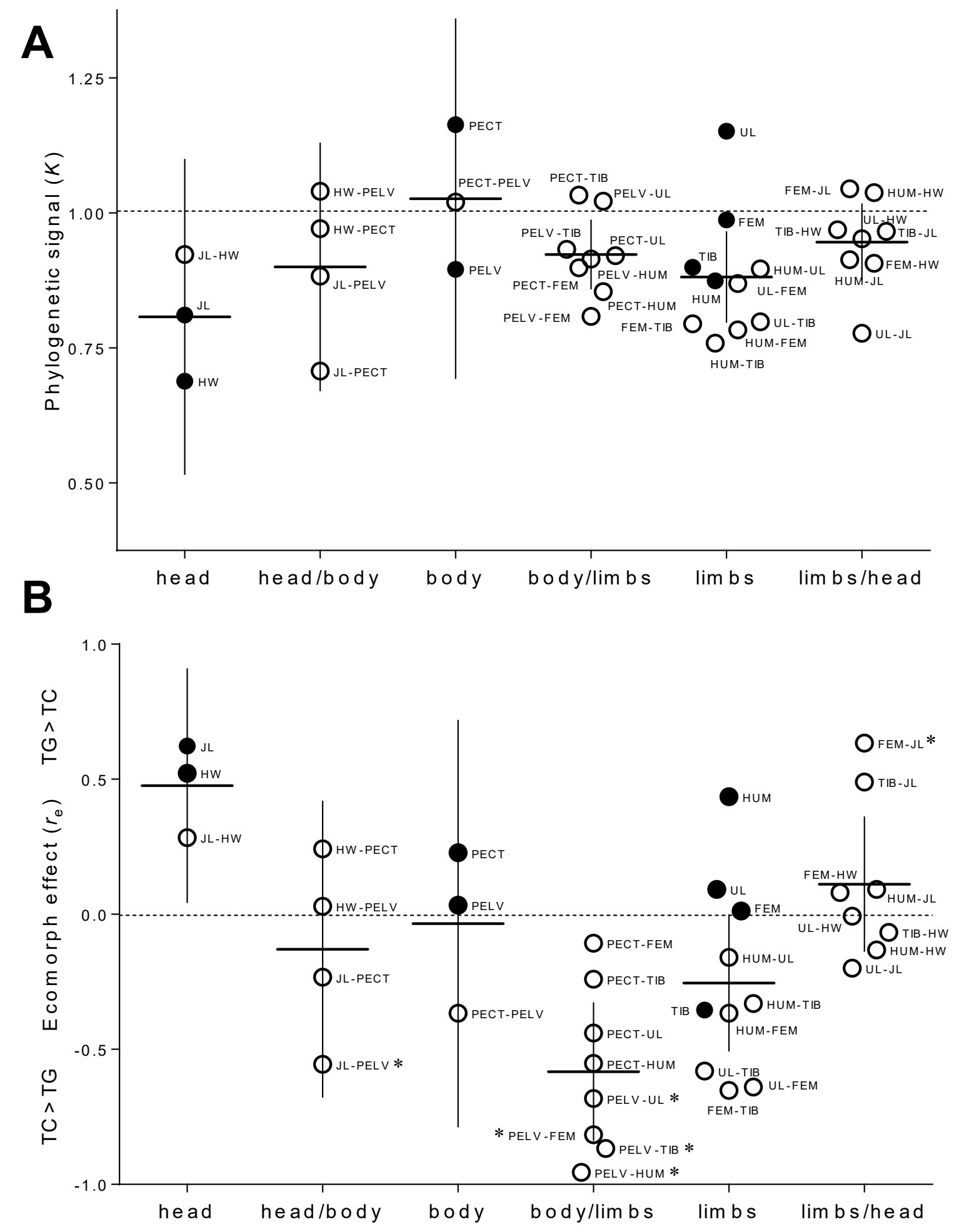


Figure 4 (previous page): Element-by-element comparisons of genetic variances (solid circles) and correlations (open circles). Elements are split into three within-module groups (head, body, and limbs) and three between-module groups (head/body, body/limb, and limb/head) and are labeled with abbreviations as in Fig. 1. Bars show means and 95\% confidence intervals for a set of point estimates within a group and are presented for visualization purposes only. $(A)$ Strength of phylogenetic signal, as estimated using Blomberg's $K$. Estimates were clustered around $K=1$, suggesting phylogenetic signal consistent with Brownian motion. $(B)$ Ecomorph effects from phylogenetic least squares, given as the evolutionary correlation $\left(r_{\mathrm{e}}\right)$. Points above the midline indicate that trunk-ground species had higher values of a given element of $\mathbf{G}$ than did trunkcrown species; the converse is true below the midline. Six genetic correlations showed a significant correlation with ecomorph (trunk-ground vs. trunk-crown; $p<.05$, denoted by $*$ ).

307 tended to be weaker in trunk-ground species than in trunk-crown species, indicating a trend

308 toward weaker integration among limb and body traits in trunk-ground species.

309 Although we did not conduct formal tests for the lone grass-bush species, A. pulchellus,

310 inspecting its genetic correlation matrix (fig. 1, table A1) shows that this species displays some

311 similarities to trunk-ground lizards. In particular, this species had weak (and occasionally

312 negative) genetic correlations between the pelvis and all limb bones, similar to all trunk-ground

313 species. A. pulchellus also showed genetic correlations between hindlimb and forelimb bones that

314 were noticeably weaker than the other two species in the Puerto Rican lineage (fig. 1, table A1).

\section{Discussion}

318 Here we present two significant findings about the evolution of quantitative genetic architecture

319 within the adaptive radiation of West Indian Anolis lizards. First, when viewed in terms of its 
320 effects on multivariate response to selection, we show that the overall structure of the Anolis $\mathbf{G}$

321 matrix retains a phylogenetic signal. Although the seven species we studied have been separated

322 for 20-44 million years, all $\mathbf{G}$ matrices predicted a very similar multivariate evolutionary

323 response, and more closely related species had more similar $\mathbf{G}$ matrices. Second, despite this

324 phylogenetic signal in the overall structure of $\mathbf{G}$, pairwise genetic correlations between limb traits

325 and body traits showed consistent signatures of convergence, suggesting that they have been

326 adaptively shaped by similar selection pressures resulting from each ecomorph's niche. In

327 particular, longer-limbed trunk-ground lizards show a decoupling of limb length and pelvis width

328 relative to shorter-limbed trunk-crown lizards, demonstrating that convergent changes in genetic

329 architecture may accompany repeated morphological adaptation. Taken together, our results

330 show that selection may alter $\mathbf{G}$ in predictable and evolutionarily consequential ways without

331 leading to major changes in its overall structure.

332 From the perspective of overall multivariate response to selection, $\mathbf{G}$ is remarkably

333 similar across the Anolis radiation, with predicted responses to selection in random directions

334 showing strong positive correlations ranging from .76 to .92 . Over the span of a few generations,

335 then, morphological divergence of species with the $\mathbf{G}$ matrices estimated here should be

336 constrained to lie along directions defined by quantitative genetic architecture. Indeed, previous

337 work has shown that divergence of these species remains aligned with the major axis of genetic

338 variation, $\mathbf{g}_{\max }$, even after $\sim 44$ million years of divergence (McGlothlin et al. 2018).

339 The similarity of the overall structure of $\mathbf{G}$ declined with greater phylogenetic distance.

340 This pattern suggests that the overall structure of $\mathbf{G}$ changes relatively slowly, remaining

341 conserved over millions of years. While similarity of $\mathbf{G}$ in closely related species may in part

342 reflect comparable patterns of contemporary selection in species in the same lineage, most 
343 similarity is likely attributable to shared evolutionary history. In addition to this phylogenetic

344 trend, we found that more distantly related species also show greater variance in random skewers

345 correlations. Although many distantly related species have dissimilar $\mathbf{G}$ matrices, some pairs

346 have highly congruent $\mathbf{G}$, a pattern that is not explained by convergent morphology. This

347 increased variance emphasizes the unpredictability of the evolution of $\mathbf{G}$ structure over longer

348 timescales.

349 When considering more subtle changes in $\mathbf{G}$ - shifts in trait-specific genetic variances and

350 correlations - we found evidence that $\mathbf{G}$ can change repeatedly and predictably in response to

351 similar selection pressures. The strongest convergence occurred in genetic correlations between

352 limb bones and pelvis width, which were significantly reduced in trunk-ground species relative to

353 trunk-crown species. In some cases, genetic correlations differed in sign between ecomorphs.

354 When this was the case, genetic correlations were usually negative in trunk-ground species and

355 positive in trunk-crown species. These results indicate that the pattern of genetic integration was

356 subtly remodeled in the transition from trunk-crown to trunk-ground ecomorphs (or vice versa),

357 most notably in the relationship between limb length and pelvis width, for which trunk-ground

358 species showed weaker genetic correlations when compared to trunk-crown species.

359 The ecomorph difference in the genetic correlations between limb length and pelvis width

360 is likely to result from a combination of directional selection and correlational selection acting on

361 these traits. Ecomorph differences in limb length have clear links to performance within their

362 characteristic habitats (Losos and Sinervo 1989; Losos 1990; Irschick and Losos 1998),

363 suggesting that they have been driven apart by divergent directional selection. The longer

364 hindlimbs of trunk-ground lizards facilitate running faster on flatter surfaces, whereas the shorter

365 hindlimbs of trunk-crown lizards are suited for a wider variety of perches (Losos 1990; Losos and 
366 Irschick 1996; Irschick and Losos 1998). Strong directional selection acting only on limb length

367 could reduce its genetic correlations with other traits; however, it is also likely that correlational

368 selection has played a role. The evolution of trunk-ground anoles from a hypothetical trunk-

369 crown ancestor would require evolution of longer legs without a concomitant increase in the

370 pelvis, which may lead to negative correlational selection to decouple the two traits. In contrast,

371 correlational selection might favor a positive correlation between the two traits in trunk-crown

372 anoles, perhaps because a matching limb and pelvic morphology would facilitate agility on

373 branches.

374 Differences in hindlimb length between trunk-crown and trunk-ground ecomorphs are

375 apparent at hatching and appear to emerge mostly via changes in developmental patterning early

376 in embryonic development rather than differences in growth (Sanger et al. 2012). The

377 developmental genetic networks underlying limb growth and development are well understood

378 (Rabinowitz and Vokes 2012), and comparative genomic evidence indicates that genes expressed

379 in these networks experienced enhanced positive selection during the radiation of anoles (Tollis

380 et al. 2018). Limb-development networks share some genes in common with the network

381 underlying development of the pelvic girdle (Sears et al. 2015). Therefore, it is likely that

382 changes in genetic correlations between limb length and pelvis involve evolutionary changes in

383 the expression of some of these shared genes. Future work should explore remodeling of these

384 networks to understand the developmental genetic underpinnings of convergent morphological

385 evolution in anoles.

386 Weaker genetic correlations between limbs and body traits likely facilitated the evolution

387 of longer hindlimbs in trunk-ground anoles without correlated changes in the rest of the body.

388 Such genetic decoupling of limbs and body may help explain the remarkable adaptability of the 
trunk-ground ecomorph. Trunk-ground anoles seem to be especially capable of colonizing new

392 locations following introduction by humans (Kolbe et al. 2004; Eales et al. 2008; Losos 2009).

393 Trunk-ground anoles also have greater species richness within islands (Losos 2009), in part

394 because they have radiated into ecologically distinct macrohabitats (Glor et al. 2003). Some of

395 this adaptability is likely due to rapid evolution in limb length, such as has been demonstrated in

396 experimental populations of $A$. sagrei (Losos et al. 1997, 2001; Kolbe et al. 2012). Although

397 comparable studies have not been conducted using trunk-crown ecomorphs, their stronger genetic

398 correlations between limb traits and body traits suggest that rapid, independent evolution of limb

399 length would not be as likely in trunk-crown species.

The genetic correlations between pelvis and limb length in the single grass-bush anole we

401 examined resemble those of trunk-ground anoles, suggesting either similar selection or common

402 ancestry, or a combination of the two. Grass-bush anoles have long hindlimbs relative to their

403 body width, suggesting that a combination of directional and correlational selection may have

404 reduced these correlations. However, A. pulchellus is likely to have evolved from a trunk-ground

405 ancestor (Poe et al. 2017), which suggests that both this species and the closely related $A$.

406 cristatellus may have inherited weakened genetic correlations between pelvis and limbs from a

407 common ancestor. In other respects, however, the genetic correlation structure of A. pulchellus is

408 dissimilar to that of $A$. cristatellus. In contrast to A. cristatellus, $A$. pulchellus appears to have

409 attained differences between the lengths of its hindlimbs and forelimbs via a reduction in the

410 genetic correlations between the two, a feature it shares with the distantly related trunk-ground

411 lizard A. lineatopus. 


\section{Conclusion}

413 The evolution of $\mathbf{G}$ in West Indian anoles illustrates how the complex interplay between selection

414 and history influences genetic architecture. G reflects neither an irresistible pattern of constraint

415 nor an easily adapted phenotype responding quickly to environmental pressures. Patterns of

416 genetic covariation have potentially influenced the pathways that selection may follow, as

417 evidenced by evolution along a deeply conserved genetic line of least resistance in this radiation

418 (McGlothlin et al. 2018). At the same time, as we show here, selection leaves an imprint, if

419 subtle, upon $\mathbf{G}$ as species diverge. We did not observe a full-scale overhaul of $\mathbf{G}$ as ecomorphs

420 evolved. However, small-scale differences in the elements of $\mathbf{G}$ involving critical morphological

421 modules arose predictably between ecomorphs and may have had substantial evolutionary

422 consequences. Our results emphasize that while genetic constraints may change as adaptation

423 proceeds, these changes need not be large to facilitate phenotypic diversification. Rather, the

424 convergent changes we observed in the individual elements of $\mathbf{G}$, particularly between the limbs

425 and the body, demonstrate that consistent selection pressures can alter underlying genetic

426 constraints in subtle ways that facilitate adaptation and influence future evolutionary potential.

\section{Acknowledgments}

430 We thank Simon Pearish and Michelle Sivilich for managing the lizard colony. Dozens of

431 undergraduates at the University of Virginia provided animal care and assistance with data

432 collection; special thanks is due to Margo Adler, Tyler Cassidy, Brian Duggar, Maridel

433 Fredericksen, Casey Furr, Jessie Handy, Bryan Hendrick, Uma Pendem, Jeff Wright, and 
434 Elizabeth Zipperle. Leleña Avila, Chris Feldman, Vince Formica, Tonia Hsieh, Melissa Losos,

435 Ashli Moore, Liam Revell, and Matt Sanford assisted with field collections. We thank Brooke

436 Bodensteiner, Vincent Farallo, Kerry Gendreau, Angela Hornsby, and Josef Uyeda for comments

437 on the manuscript, and Luke Harmon, Gabriel Marroig, Emília Martins, and Liam Revell for

438 helpful discussions. This work was supported by the National Science Foundation (grant numbers

439 DEB 0519658 and 0650078 to E.D.B. III and DEB 0519777 and 0722475 to J.B.L.), University

440 of Virginia, and Virginia Tech. The authors declare that there are no conflicts of interest.

\section{Statement of Authorship}

444 J.B.L. and E.D.B. III conceived the study; J.W.M. and J.J.K. contributed to study design; J.W.M.,

445 J.J.K., J.B.L., and E.D.B. III performed field collections; J.W.M. and E.D.B. III oversaw the

446 breeding experiment; J.W.M., M.E.K., and H.V.W. collected data; J.W.M. analyzed data; J.W.M.

447 drafted the manuscript and all authors contributed to the final version of the manuscript.

\section{Data and Code Availability}

451 Raw data for estimating $\mathbf{G}$ matrices are available in a Dryad Data Repository from a previous

452 publication (https://datadryad.org/stash/dataset/doi:10.5061/dryad.pt2g084). All code and

453 processed data are available at https://github.com/joelmcg/AnolisG and will be archived in Dryad

454 upon manuscript acceptance. 


\section{Literature Cited}

457 Agrawal, A. F., E. D. Brodie, III, and L. H. Rieseberg. 2001. Possible consequences of genes of major effect: transient changes in the G-matrix. Genetica 112:33-43.

459 Aguirre, J. D., E. Hine, K. McGuigan, and M. W. Blows. 2014. Comparing G: multivariate analysis of genetic variation in multiple populations. Heredity 112:21-29.

Arnold, S. J., R. Bürger, P. A. Hohenlohe, B. C. Ajie, and A. G. Jones. 2008. Understanding the evolution and stability of the G-matrix. Evolution 62:2451-2461.

Arnold, S. J., M. E. Pfrender, and A. G. Jones. 2001. The adaptive landscape as a conceptual bridge between micro- and macroevolution. Genetica 112-113:9-32.

Bégin, M., and D. A. Roff. 2003. The constancy of the $\mathbf{G}$ matrix through species divergence and the effects of quantitative genetic constraints on phenotypic evolution: a case study in crickets. Evolution 57:1107-1120.

- 2004. From micro- to macroevolution through quantitative genetic variation: positive evidence from field crickets. Evolution 58:2287-2304.

Beuttell, K., and J. B. Losos. 1999. Ecological morphology of Caribbean anoles. Herpetological Monographs:1-28.

Björklund, M., A. Husby, and L. Gustafsson. 2013. Rapid and unpredictable changes of the Gmatrix in a natural bird population over 25 years. Journal of Evolutionary Biology 26:113.

Blomberg, S. P., T. Garland, and A. R. Ives. 2003. Testing for phylogenetic signal in comparative data: Behavioral traits are more labile. Evolution 57:717-745. 
Blows, M. W., and A. A. Hoffmann. 2005. A reassessment of genetic limits to evolutionary change. Ecology 86:1371-1384.

Bolstad, G. H., T. F. Hansen, C. Pelabon, M. Falahati-Anbaran, R. Perez-Barrales, and W. S. Armbruster. 2014. Genetic constraints predict evolutionary divergence in Dalechampia blossoms. Philosophical Transactions of the Royal Society B-Biological Sciences 369.

Brodie, E. D., III. 1989. Genetic correlations between morphology and antipredator behaviour in natural populations of the garter snakes Thamnophis ordinoides. Nature 342:542-543.

-. 1992. Correlational selection for color pattern and antipredator behavior in the garter snake Thamnophis ordinoides. Evolution 46:1284-1298.

Cano, J. M., A. Laurila, J. Palo, and J. Merilä. 2004. Population differentiation in G matrix structure due to natural selection in Rana temporaria. Evolution 58:2013-2020. variance-covariance matrix under continuous directional selection on a complex behavioural phenotype. Proceedings of the Royal Society B-Biological Sciences 282. selection. Journal of Theoretical Biology 110:155-171.

496 Cheverud, J. M., and G. Marroig. 2007. Comparing covariance matrices: random skewers method compared to the common principal components model. Genetics and Molecular Biology $30: 461-469$. 
Cox, R. M., C. L. Cox, J. W. McGlothlin, D. C. Card, A. L. Andrew, and T. A. Castoe. 2017. Hormonally mediated increases in sex-biased gene expression accompany the breakdown of between-sex genetic correlations in a sexually dimorphic lizard. American Naturalist 189:315-332.

Delph, L. F., J. C. Steven, I. A. Anderson, C. R. Herlihy, and E. D. Brodie, III. 2011. Elimination of a genetic correlation between the sexes via artificial correlational selection. Evolution

Dobzhansky, T. 1937, Genetics and the Origin of Species, Columbia Univ. Press. genetic variance-covariance matrix within a natural population. American Naturalist 171:291-304.

Eales, J., R. S. Thorpe, and A. Malhotra. 2008. Weak founder effect signal in a recent

512 Eroukhmanoff, F., and E. I. Svensson. 2011. Evolution and stability of the G-matrix during the colonization of a novel environment. Journal of Evolutionary Biology 24:1363-1373.

514 Falconer, D. S., and T. F. C. MacKay. 1996, Introduction to Quantitative Genetics. Harlow, England, Prentice Hall.

516 Gilmour, A. R., B. J. Gogel, B. R. Cullis, and R. Thompson. 2009, ASReml User Guide Release 3.0. Hemel Hempstead, UK, VSN International Ltd.

518 Glor, R. E., J. J. Kolbe, R. Powell, A. Larson, and J. B. Losos. 2003. Phylogenetic analysis of ecological and morphological diversification in Hispaniolan trunk-ground anoles (anolis cybotes group). Evolution 57:2383-2397. 
521 Grant, P. R., and B. R. Grant. 1995. Predicting microevolutionary responses to directional selection on heritable variation. Evolution 49:241-251.

523 Hadfield, J. D., A. Nutall, D. Osorio, and I. P. F. Owens. 2007. Testing the phenotypic gambit:

524 phenotypic, genetic and environmental correlations of colour. Journal of Evolutionary Biology 20:549-557.

526 Hansen, T. F., and D. Houle. 2008. Measuring and comparing evolvability and constraint in multivariate characters. Journal of Evolutionary Biology 21:1201-1219.

528 Harmon, L. J., and R. E. Glor. 2010. Poor statistical performance of the Mantel test in phylogenetic comparative analyses. Evolution 64:2173-2178.

530 Harmon, L. J., J. J. Kolbe, J. M. Cheverud, and J. B. Losos. 2005. Convergence and the multidimensional niche. Evolution 59:409-421.

532 Hine, E., S. F. Chenoweth, H. D. Rundle, and M. W. Blows. 2009. Characterizing the evolution of genetic variance using genetic covariance tensors. Philosophical Transactions of the

535 Houle, D., G. H. Bolstad, K. van der Linde, and T. F. Hansen. 2017. Mutation predicts 40 million years of fly wing evolution. Nature 548:447-+.

537 Houle, D., and K. Meyer. 2015. Estimating sampling error of evolutionary statistics based on genetic covariance matrices using maximum likelihood. Journal of Evolutionary Biology

540 Irschick, D. J., and J. B. Losos. 1998. A comparative analysis of the ecological significance of 
542 Jones, A. G., S. J. Arnold, and R. Bürger. 2003. Stability of the G-matrix in a population

543 experiencing pleiotropic mutation, stabilizing selection, and genetic drift. Evolution

$544 \quad 57: 1747-1760$.

$545-$ - 2004. Evolution and stability of the G-matrix on a landscape with a moving optimum.

$546 \quad$ Evolution 58:1639-1654.

547 Jones, A. G., R. Bürger, and S. J. Arnold. 2014. Epistasis and natural selection shape the

548 mutational architecture of complex traits. Nature Communications 5.

549 Jones, A. G., R. Bürger, S. J. Arnold, P. A. Hohenlohe, and J. C. Uyeda. 2012. The effects of

550 stochastic and episodic movement of the optimum on the evolution of the G-matrix and

551 the response of the trait mean to selection. Journal of Evolutionary Biology 25:2210-

$552 \quad 2231$.

553 Kim, S. 2015. ppcor: An R package for a fast calculation to semi-partial correlation coefficients.

$554 \quad$ Commun Stat Appl Methods 22:665-674.

555 Kolbe, J. J., R. E. Glor, L. R. G. Schettino, A. C. Lara, A. Larson, and J. B. Losos. 2004. Genetic

556 variation increases during biological invasion by a Cuban lizard. Nature 431:177-181.

557 Kolbe, J. J., M. Leal, T. W. Schoener, D. A. Spiller, and J. B. Losos. 2012. Founder effects

558 persist despite adaptive differentiation: a field experiment with lizards. Science 335:1086-

5591089.

560 Kolbe, J. J., L. J. Revell, B. Szekely, E. D. Brodie, and J. B. Losos. 2011. Convergent evolution

561 of phenotypic integration and Its alignment with morphological diversification in

562 Caribbean Anolis ecomorphs. Evolution 65:3608-3624.

563 Lande, R. 1979. Quantitative genetic analysis of multivariate evolution, applied to brain:body

$564 \quad$ size allometry. Evolution 33:402-416. 
$565-$. 1980. The genetic covariance between characters maintained by pleiotropic mutations.

$566 \quad$ Genetics 94:203-215.

567 Losos, J. B. 1990. Ecomorphology, performance capability, and scaling of West Indian Anolis

568 lizards: an evolutionary analysis. Ecological Monographs 60:369-388.

569 - 1994. Integrative approaches to evolutionary ecology: Anolis lizards as model systems.

$570 \quad$ Annual Review of Ecology and Systematics 25:467-493.

571 - 2009, Lizards in an Evolutionary Tree: Ecology and Adaptive Radiation of Anoles. Berkeley, $572 \quad$ Univ. of California Press.

573 -. 2011. Convergence, adaptation, and constraint. Evolution 65:1827-1840.

574 Losos, J. B., and D. J. Irschick. 1996. The effect of perch diameter on escape behaviour of Anolis

575 lizards: laboratory predictions and field tests. Animal Behaviour 51:593-602.

576 Losos, J. B., T. R. Jackman, A. Larson, K. de Queiroz, and L. Rodríguez-Schettino. 1998.

577 Contingency and determinism in replicated adaptive radiations of island lizards. Science

$578 \quad 279: 2115-2118$.

579 Losos, J. B., T. W. Schoener, K. I. Warheit, and D. Creer. 2001. Experimental studies of adaptive 580 differentiation in Bahamian Anolis lizards. Genetica 112:399-415.

581 Losos, J. B., and B. Sinervo. 1989. The effects of morphology and perch diameter on sprint

582 performance of Anolis lizards. Journal of Experimental Biology 145:23-30.

583 Losos, J. B., K. I. Warheit, and T. W. Schoener. 1997. Adaptive differentiation following

584 experimental island colonization in Anolis lizards. Nature 387:70-73.

585 Mahler, D. L., T. Ingram, L. J. Revell, and J. B. Losos. 2013. Exceptional convergence on the 586 macroevolutionary landscape in island lizard radiations. Science 341:292-295. 
Marroig, G., and J. M. Cheverud. 2001. A comparison of phenotypic variation and covariation patterns and the role of phylogeny. Ecology, and ontogeny during cranial evolution of new world monkeys. Evolution 55:2576-2600.

Martins, E. P., and T. F. Hansen. 1997. Phylogenies and the comparative method: a general approach to incorporating phylogenetic information into the analysis of interspecific data. Brodie, III. 2018. Adaptive radiation along a deeply conserved genetic line of least leads to genetic integration of body size and an attractive plumage trait in dark-eyed juncos. Evolution 59:658-671.

McGuigan, K. 2006. Studying phenotypic evolution using multivariate quantitative genetics. Molecular Ecology 15:883-896.

601 McGuigan, K., S. F. Chenoweth, and M. W. Blows. 2005. Phenotypic divergence along lines of genetic variance. American Naturalist 165:32-43.

603 Melo, D., G. Garcia, A. Hubbe, A. P. Assis, and G. Marroig. 2015. EvolQG - An R package for evolutionary quantitative genetics. F1000Res 4:925.

605 Merilä, J., and M. Björklund. 2004. Phenotypic integration as a constraint and adaptation, Pages Ecology and Evolution of Complex Phenotypes. Oxford, Oxford Univ. Press. R language. Bioinformatics 20:289-290. 
610 Phillips, P. C., and S. J. Arnold. 1989. Visualizing multivariate selection. Evolution 43:1209-

$611 \quad 1222$.

612 Poe, S., A. Nieto-Montes de Oca, O. Torres-Carvajal, K. de Queiroz, J. A. Velasco, B. Truett, L.

613 N. Gray et al. 2017. A phylogenetic, biogeographic, and taxonomic study of all extant

614 species of Anolis (Squamata; Iguanidae). Systematic Biology 66:663-697.

615 R Core Team. 2019. R: A language and environment for statistical computing. . Vienna, Austria,

616 R Foundation for Statistical Computing.

617 Rabinowitz, A. H., and S. A. Vokes. 2012. Integration of the transcriptional networks regulating

618 limb morphogenesis. Developmental Biology 368:165-180.

619 Revell, L. J. 2007. The G matrix under fluctuating correlational mutation and selection.

$620 \quad$ Evolution 61:1857-1872.

621 - 2012. phytools: an R package for phylogenetic comparative biology (and other things).

622 Methods in Ecology and Evolution 3:217-223.

623 Revell, L. J., D. L. Mahler, J. R. Sweeney, M. Sobotka, V. E. Fancher, and J. B. Losos. 2010.

624 Nonlinear selection and the evolution of variances and covariances for continuous

625 characters in an anole. Journal of Evolutionary Biology 23:407-421.

626 Roff, D. A. 1997, Evolutionary Quantitative Genetics. New York, Chapman \& Hall.

627 Roff, D. A., and D. J. Fairbairn. 2012. A test of the hypothesis that correlational selection

628 generates genetic correlations. Evolution 66:2953-2960.

629 Sanger, T. J., L. J. Revell, J. J. Gibson-Brown, and J. B. Losos. 2012. Repeated modification of

630 early limb morphogenesis programmes underlies the convergence of relative limb length

631 in Anolis lizards. Proceedings of the Royal Society B-Biological Sciences 279:739-748. 
632 Schluter, D. 1996. Adaptive radiation along genetic lines of least resistance. Evolution 50:1766-

6331774.

634 Sears, K. E., T. D. Capellini, and R. Diogo. 2015. On the serial homology of the pectoral and 635 pelvic girdles of tetrapods. Evolution 69:2543-2555.

636 Steppan, S. J., P. C. Phillips, and D. Houle. 2002. Comparative quantitative genetics: evolution of 637 the G matrix. Trends in Ecology \& Evolution 17:320-327.

638 Steven, J. C., I. A. Anderson, E. D. Brodie III, and L. F. Delph. 2020. Rapid reversal of a potentially constraining genetic covariance between leaf and flower traits in Silene

Tollis, M., E. D. Hutchins, J. Stapley, S. M. Rupp, W. L. Eckalbar, I. Maayan, E. Lasku et al. 2018. Comparative genomics reveals accelerated evolution in conserved pathways during the diversification of anole lizards. Genome Biology and Evolution 10:489-506.

644 Turelli, M. 1988. Phenotypic evolution, constant covariances, and the maintenance of additive variance. Evolution 42:1342-1347.

646 Walsh, B., and M. W. Blows. 2009. Abundant genetic variation plus strong selection $=$ multivariate genetic constraints: a geometric view of adaptation. Annual Review of Ecology Evolution and Systematics 40:41-59.

649 Walter, G. M., J. D. Aguirre, M. W. Blows, and D. Ortiz-Barrientos. 2018. Evolution of genetic variance during adaptive radiation. American Naturalist 191:E108-E128.

651 Williams, E. E. 1972. The origin of faunas. Evolution of lizard congeners in a complex island 652 fauna: a trial analysis. Evolutionary Biology 6:47-89.

653 Wood, S. 2012. mgcv: Mixed GAM Computation Vehicle with GCV/AIC/REML smoothness 654 estimation. 
bioRxiv preprint doi: https://doi.org/10.1101/2021.02.18.431064; this version posted February 18, 2021. The copyright holder for this preprint

(which was not certified by peer review) is the author/funder, who has granted bioRxiv a license to display the preprint in perpetuity. It is made available under aCC-BY-NC-ND 4.0 International license.

655 Zheng, Y. C., and J. J. Wiens. 2016. Combining phylogenomic and supermatrix approaches, and 656 a time-calibrated phylogeny for squamate reptiles (lizards and snakes) based on 52 genes 657 and 4162 species. Molecular Phylogenetics and Evolution 94:537-547. 


\section{Appendix}

\section{Supplemental Tables}

Table A1: G matrices and matrices of heritabilities $\left(h^{2}\right.$, diagonal) and genetic correlations $\left(r_{g}\right.$, off-diagonal) for seven Anolis species. Approximate standard errors for are shown below each matrix. G matrices and standard errors are reprinted from McGlothlin et al. (2018). Although we did not conduct formal likelihood-ratio tests, parameters that exceeded their standard errors by a factor of two are shown in bold, which provides a guide to statistical significance. Traits are abbreviated as follows: $\mathrm{JL}=$ jaw length, $\mathrm{HW}=$ head width, $\mathrm{PECT}=$ pectoral width, $\mathrm{PELV}=$ pelvic width, $\mathrm{HUM}=$ humerus, $\mathrm{UL}=$ ulna, FEM = femur, and TIB = tibia. All traits were natural$\log$ transformed and size-corrected for analysis.

Anolis cristatellus (Trunk-ground, Puerto Rico)

$\begin{array}{lrrrrrrrr}\mathbf{G}\left(\times 10^{-3}\right) & & & & & & & \\ & \text { JL } & \text { HW } & \text { PECT } & \text { PELV } & \text { HUM } & \text { UL } & \text { FEM } & \text { TIB } \\ \text { JL } & \mathbf{. 3 2 9} & & & & & & & \\ \text { HW } & \mathbf{. 0 9 4} & \mathbf{. 4 4 9} & & & & & & \\ \text { PECT } & -.083 & \mathbf{. 3 4 9} & \mathbf{1 . 4 2 6} & & & & & \\ \text { PELV } & -.089 & \mathbf{. 2 4 0} & \mathbf{. 4 8 7} & \mathbf{. 5 4 6} & & & & \\ \text { HUM } & \mathbf{. 2 9 3} & .071 & \mathbf{- . 3 7 1} & \mathbf{- . 1 6 8} & \mathbf{1 . 4 4 1} & & & \\ \text { UL } & .079 & .075 & -.098 & .017 & \mathbf{1 . 0 0 8} & \mathbf{1 . 0 8 7} & & \\ \text { FEM } & \mathbf{. 2 0 8} & .030 & -.053 & -.051 & \mathbf{. 9 0 4} & \mathbf{. 7 3 1} & \mathbf{. 8 0 9} & \\ \text { TIB } & \mathbf{. 2 6 8} & .009 & \mathbf{- . 1 7 2} & -.081 & \mathbf{. 9 4 5} & \mathbf{. 7 8 0} & \mathbf{. 7 8 3} & \mathbf{. 9 4 9} \\ & & & & & & & & \\ \text { SE }\left(\times 10^{-3}\right) & & & & & & & \\ & \text { JL } & \text { HW } & \text { PECT } & \text { PELV } & \text { HUM } & \text { UL } & \text { FEM } & \text { TIB } \\ \text { JL } & .052 & & & & & & & \\ \text { HW } & .029 & .048 & & & & & & \\ \text { PECT } & .053 & .066 & .170 & & & & & \\ \text { PELV } & .056 & .049 & .093 & .113 & & & & \\ \text { HUM } & .057 & .067 & .128 & .090 & .200 & & & \\ \text { UL } & .053 & .063 & .119 & .087 & .144 & .175 & & \\ \text { FEM } & .035 & .042 & .077 & .058 & .093 & .085 & .071 & \\ \text { TIB } & .037 & .043 & .081 & .060 & .096 & .089 & .067 & .076\end{array}$


Anolis cristatellus (continued)

$h^{2} / r_{g}$

JL HW PECT PELV HUM UL FEM TIB

JL $\quad \mathbf{4 5 8}$

$\begin{array}{lll}\text { HW } & .245 & .353\end{array}$

$\begin{array}{llll}\text { PECT } & -.122 & \mathbf{4 3 5} & \mathbf{. 3 0 6}\end{array}$

$\begin{array}{lllll}\text { PELV } & -.210 & \mathbf{. 4 8 4} & \mathbf{. 5 5 2} & \mathbf{. 1 9 6}\end{array}$

$\begin{array}{llllll}\text { HUM } & \mathbf{4 2 5} & .088 & \mathbf{- . 2 5 9} & -.190 & \mathbf{. 2 3 1}\end{array}$

$\begin{array}{llllllll}\text { UL } & .132 & .108 & -.078 & .022 & \mathbf{. 8 0 5} & \mathbf{. 1 8 5}\end{array}$

$\begin{array}{llllllll}\text { FEM } & \mathbf{. 4 0 3} & .049 & -.049 & -.076 & \mathbf{. 8 3 7} & \mathbf{. 7 7 9} & \mathbf{. 4 8 2}\end{array}$

$\begin{array}{lllllllll}\text { TIB } & \mathbf{4 8 0} & .014 & \mathbf{- . 1 4 8} & -.113 & \mathbf{. 8 0 8} & \mathbf{. 7 6 8} & \mathbf{. 8 9 4} & \mathbf{. 5 6 1}\end{array}$

$h^{2} / r_{g} \mathrm{SE}$

JL HW PECT PELV HUM UL FEM TIB

$\mathrm{JL} \quad .057$

$\begin{array}{lll}\mathrm{HW} & .068 \quad .028\end{array}$

$\begin{array}{llll}\text { PECT } & .079 & .073 & .029\end{array}$

$\begin{array}{lllll}\text { PELV } & .130 & .093 & .092 & .037\end{array}$

$\begin{array}{llllll}\text { HUM } & .081 & .082 & .084 & .101 & .028\end{array}$

$\begin{array}{lllllll}\text { UL } & .091 & .090 & .094 & .111 & .057 & .027\end{array}$

$\begin{array}{llllllll}\text { FEM } & .066 & .068 & .072 & .087 & .049 & .058 & .025\end{array}$

$\begin{array}{lllllllll}\text { TIB } & .063 & .066 & .069 & .085 & .051 & .057 & .017 & .023\end{array}$ 
Anolis evermanni (Trunk-crown, Puerto Rico)

\begin{tabular}{lrrrrrrrr}
$\mathbf{G}\left(\times 10^{-3}\right)$ & & & & & & & \\
& \multicolumn{1}{l}{ JL } & HW & PECT & PELV & HUM & UL & FEM & TIB \\
JL & $\mathbf{. 2 5 1}$ & & & & & & & \\
HW & -.013 & $\mathbf{. 3 1 4}$ & & & & & & \\
PECT & .016 & $\mathbf{. 4 1 1}$ & $\mathbf{1 . 0 6 2}$ & & & & & \\
PELV & -.017 & $\mathbf{. 1 8 3}$ & $\mathbf{. 4 3 5}$ & $\mathbf{. 6 2 3}$ & & & & \\
HUM &. $\mathbf{1 4 3}$ & .022 & .051 & .139 & $\mathbf{. 8 6 6}$ & & & \\
UL & $\mathbf{. 1 4 1}$ & -.026 & .097 & .145 & $\mathbf{. 8 8 4}$ & $\mathbf{. 9 7 1}$ & & \\
FEM & .070 & .040 & $\mathbf{. 2 2 8}$ & $\mathbf{. 2 7 9}$ & $\mathbf{. 8 5 0}$ & $\mathbf{. 9 2 2}$ & $\mathbf{1 . 2 2 4}$ & \\
TIB & $\mathbf{. 1 2 1}$ & .047 & .178 & $\mathbf{. 2 5 8}$ & $\mathbf{. 9 7 1}$ & $\mathbf{1 . 0 6 4}$ & $\mathbf{1 . 4 2 7}$ & $\mathbf{1 . 7 5 1}$
\end{tabular}

$\operatorname{SE}\left(\times 10^{-3}\right)$

JL HW PECT PELV HUM UL FEM TIB

JL $\quad .029$

$\begin{array}{lll}\text { HW } & .027 \quad .049\end{array}$

$\begin{array}{llll}\text { PECT } & .048 & .069 & .163\end{array}$

$\begin{array}{lllll}\text { PELV } & .040 & .054 & .099 & .146\end{array}$

$\begin{array}{llllll}\text { HUM } & .049 & .061 & .110 & .091 & .160\end{array}$

$\begin{array}{lllllll}\text { UL } & .049 & .062 & .113 & .093 & .135 & .156\end{array}$

$\begin{array}{llllllll}\text { FEM } & .041 & .054 & .098 & .083 & .108 & .110 & .117\end{array}$

$\begin{array}{lllllllll}\text { TIB } & .048 & .064 & .114 & .097 & .124 & .128 & .125 & .174\end{array}$

$h^{2} / r_{g}$

JL HW PECT PELV HUM UL FEM TIB

JL $\quad \mathbf{4 1 5}$

HW $\quad-.047 \quad .244$

$\begin{array}{llll}\text { PECT } & .031 & \mathbf{7 1 2} & \mathbf{2 8 0}\end{array}$

$\begin{array}{lllll}\text { PELV } & -.043 & \mathbf{. 4 1 4} & \mathbf{. 5 3 5} & \mathbf{. 2 2 7}\end{array}$

$\begin{array}{llllll}\text { HUM } & \mathbf{. 3 0 6} & .042 & .053 & .189 & \mathbf{. 1 9 4}\end{array}$

$\begin{array}{llllllll}\text { UL } & \mathbf{2 8 6} & -.046 & .096 & .186 & \mathbf{. 9 6 4} & \mathbf{. 2 1 2}\end{array}$

$\begin{array}{lllllllll}\text { FEM } & .126 & .064 & \mathbf{. 2 0 0} & \mathbf{. 3 1 9} & \mathbf{. 8 2 5} & \mathbf{. 8 4 6} & \mathbf{. 5 9 9}\end{array}$

$\begin{array}{lllllllll}\text { TIB } & .182 & .064 & .131 & .247 & \mathbf{. 7 8 8} & \mathbf{. 8 1 6} & \mathbf{. 9 7 5} & \mathbf{. 7 0 4}\end{array}$

$h^{2} / r_{g} \mathrm{SE}$

JL HW PECT PELV HUM UL FEM TIB

$\mathrm{JL} \quad .033$

$\begin{array}{lll}\mathrm{HW} & .097 \quad .032\end{array}$

$\begin{array}{llll}\text { PECT } & .094 & .077 & .035\end{array}$

$\begin{array}{lllll}\text { PELV } & .101 & .108 & .106 & .048\end{array}$

$\begin{array}{llllll}\text { HUM } & .096 & .117 & .117 & .122 & .032\end{array}$

$\begin{array}{lllllll}\text { UL } & .092 & .113 & .111 & .117 & .044 & .029\end{array}$

$\begin{array}{llllllll}\text { FEM } & .072 & .087 & .083 & .089 & .066 & .053 & .030\end{array}$

$\begin{array}{lllllllll}\text { TIB } & .069 & .085 & .083 & .089 & .071 & .057 & .011 & .034\end{array}$ 
Anolis grahami (Trunk-crown, Jamaica)

\begin{tabular}{|c|c|c|c|c|c|c|c|c|}
\hline \multicolumn{9}{|c|}{$\mathbf{G}\left(\times 10^{-3}\right)$} \\
\hline & $\mathrm{JL}$ & HW & PECT & PELV & HUM & UL & FEM & TIB \\
\hline JL & .246 & & & & & & & \\
\hline HW & .218 & .296 & & & & & & \\
\hline PECT & .127 & .122 & .351 & & & & & \\
\hline PELV & .193 & .126 & .173 & .704 & & & & \\
\hline HUM & .152 & .067 & .167 & .264 & 1.003 & & & \\
\hline UL & .129 & .131 & .122 & .130 & .856 & 1.171 & & \\
\hline FEM & .126 & -.005 & .081 & .186 & .625 & .559 & .510 & \\
\hline TIB & .146 & .034 & .171 & .269 & .732 & .724 & .549 & .648 \\
\hline \multicolumn{9}{|c|}{$\mathrm{SE}\left(\times 10^{-3}\right)$} \\
\hline & $\mathrm{JL}$ & HW & PECT & PELV & HUM & UL & FEM & TIB \\
\hline $\mathrm{JL}$ & .049 & & & & & & & \\
\hline HW & .051 & .082 & & & & & & \\
\hline PECT & .064 & .081 & .151 & & & & & \\
\hline PELV & .068 & .084 & .113 & .169 & & & & \\
\hline HUM & .140 & .186 & .238 & .176 & .465 & & & \\
\hline UL & .103 & .133 & .177 & .186 & .323 & .405 & & \\
\hline FEM & .052 & .099 & .139 & .111 & .230 & .191 & .170 & \\
\hline $\mathrm{TIB}$ & .056 & .102 & .145 & .104 & .230 & .181 & .163 & .179 \\
\hline \multicolumn{9}{|l|}{$h^{2} / r_{g}$} \\
\hline & $\mathrm{JL}$ & HW & PECT & PELV & HUM & UL & FEM & TIB \\
\hline $\mathrm{JL}$ & .421 & & & & & & & \\
\hline HW & .807 & .240 & & & & & & \\
\hline PECT & .434 & .377 & .133 & & & & & \\
\hline PELV & .465 & .277 & .349 & .277 & & & & \\
\hline HUM & .307 & .123 & .281 & .315 & .168 & & & \\
\hline UL & .240 & .222 & .191 & .143 & .790 & .159 & & \\
\hline FEM & .355 & -.013 & .191 & .311 & .873 & .723 & .453 & \\
\hline TIB & .367 & .076 & .358 & .399 & .908 & .831 & .955 & .544 \\
\hline \multicolumn{9}{|l|}{$h^{2} / r_{g} \mathrm{SE}$} \\
\hline & $\mathrm{JL}$ & HW & PECT & PELV & HUM & UL & FEM & TIB \\
\hline $\mathrm{JL}$ & .056 & & & & & & & \\
\hline HW & .092 & .056 & & & & & & \\
\hline PECT & .190 & .229 & .054 & & & & & \\
\hline PELV & .134 & .173 & .210 & .054 & & & & \\
\hline HUM & .266 & .341 & .392 & .192 & .072 & & & \\
\hline UL & .188 & .221 & .281 & .199 & .155 & .050 & & \\
\hline FEM & .136 & .249 & .323 & .171 & .165 & .160 & .122 & \\
\hline TIB & .127 & .231 & .289 & .134 & .165 & .124 & .037 & .110 \\
\hline
\end{tabular}


Anolis lineatopus (Trunk-ground, Jamaica)

\begin{tabular}{|c|c|c|c|c|c|c|c|c|}
\hline \multicolumn{9}{|c|}{$\mathbf{G}\left(\times 10^{-3}\right)$} \\
\hline & $\mathrm{JL}$ & HW & PECT & PELV & HUM & UL & FEM & TIB \\
\hline $\mathrm{JL}$ & .442 & & & & & & & \\
\hline HW & .286 & .263 & & & & & & \\
\hline PECT & .385 & .290 & .750 & & & & & \\
\hline PELV & .193 & .132 & .343 & .916 & & & & \\
\hline HUM & .321 & .240 & .223 & -.016 & .968 & & & \\
\hline UL & .412 & .297 & .308 & -.200 & .942 & 1.047 & & \\
\hline FEM & .423 & .180 & .547 & .228 & .530 & .540 & 1.013 & \\
\hline TIB & .368 & .145 & .528 & .182 & .464 & .495 & .864 & \\
\hline \multicolumn{9}{|c|}{$\mathrm{SE}\left(\times 10^{-3}\right)$} \\
\hline & $\mathrm{JL}$ & HW & PECT & PELV & HUM & UL & FEM & TIB \\
\hline $\mathrm{JL}$ & .103 & & & & & & & \\
\hline HW & .059 & .090 & & & & & & \\
\hline PECT & .101 & .100 & .309 & & & & & \\
\hline PELV & .158 & .139 & .254 & .352 & & & & \\
\hline HUM & .127 & .103 & .213 & .200 & .291 & & & \\
\hline UL & .106 & .104 & .186 & .174 & .240 & .270 & & \\
\hline FEM & .168 & .130 & .233 & .256 & .255 & .248 & .346 & \\
\hline $\mathrm{TIB}$ & .147 & .117 & .212 & .227 & .226 & .222 & .295 & .272 \\
\hline \multicolumn{9}{|l|}{$h^{2} / r_{g}$} \\
\hline & $\mathrm{JL}$ & HW & PECT & PELV & HUM & UL & FEM & TIB \\
\hline $\mathrm{JL}$ & .536 & & & & & & & \\
\hline HW & .837 & .177 & & & & & & \\
\hline PECT & .668 & .652 & .151 & & & & & \\
\hline PELV & .303 & .269 & .414 & .253 & & & & \\
\hline HUM & .491 & .475 & .262 & -.017 & .161 & & & \\
\hline UL & .605 & .566 & .348 & -.204 & .936 & .169 & & \\
\hline FEM & .633 & .349 & .627 & .237 & .535 & .525 & .645 & \\
\hline TIB & .610 & .311 & .672 & .209 & .519 & .533 & .945 & .587 \\
\hline \multicolumn{9}{|l|}{$h^{2} / r_{g} \mathrm{SE}$} \\
\hline & $\mathrm{JL}$ & HW & PECT & PELV & HUM & UL & FEM & TIB \\
\hline $\mathrm{JL}$ & .089 & & & & & & & \\
\hline HW & .114 & .056 & & & & & & \\
\hline PECT & .158 & .206 & .059 & & & & & \\
\hline PELV & .217 & .265 & .263 & .087 & & & & \\
\hline HUM & .167 & .196 & .251 & .223 & .044 & & & \\
\hline UL & .118 & .178 & .223 & .177 & .071 & .040 & & \\
\hline FEM & .143 & .237 & .202 & .232 & .201 & .196 & .155 & \\
\hline TIB & .146 & .238 & .188 & .233 & .206 & .196 & .029 & .143 \\
\hline
\end{tabular}


Anolis pulchellus (Grass-bush, Puerto Rico)

\begin{tabular}{|c|c|c|c|c|c|c|c|c|}
\hline \multicolumn{9}{|c|}{$\mathbf{G}\left(\times 10^{-3}\right)$} \\
\hline & $\mathrm{JL}$ & HW & PECT & PELV & HUM & UL & FEM & TIB \\
\hline JL & .084 & & & & & & & \\
\hline HW & .080 & .157 & & & & & & \\
\hline PECT & .222 & .215 & .895 & & & & & \\
\hline PELV & .070 & .065 & .300 & .766 & & & & \\
\hline HUM & .148 & .040 & .153 & -.036 & .745 & & & \\
\hline UL & .180 & .080 & .214 & -.152 & .773 & .982 & & \\
\hline FEM & .092 & .040 & .156 & .126 & .475 & .524 & .701 & \\
\hline TIB & .089 & .030 & .136 & .134 & .403 & .524 & .648 & .723 \\
\hline \multicolumn{9}{|c|}{$\mathrm{SE}\left(\times 10^{-3}\right)$} \\
\hline & $\mathrm{JL}$ & HW & PECT & PELV & HUM & UL & FEM & TIB \\
\hline $\mathrm{JL}$ & .050 & & & & & & & \\
\hline HW & .040 & .059 & & & & & & \\
\hline PECT & .075 & .070 & .268 & & & & & \\
\hline PELV & .066 & .061 & .192 & .244 & & & & \\
\hline HUM & .072 & .068 & .163 & .127 & .204 & & & \\
\hline UL & .082 & .076 & .155 & .145 & .197 & .254 & & \\
\hline FEM & .054 & .053 & .110 & .083 & .133 & .118 & .156 & \\
\hline $\mathrm{TIB}$ & .054 & .045 & .087 & .082 & .141 & .143 & .148 & .168 \\
\hline \multicolumn{9}{|l|}{$h^{2} / r_{g}$} \\
\hline & $\mathrm{JL}$ & HW & PECT & PELV & HUM & UL & FEM & TIB \\
\hline $\mathrm{JL}$ & .076 & & & & & & & \\
\hline HW & .701 & .124 & & & & & & \\
\hline PECT & .810 & .574 & .211 & & & & & \\
\hline PELV & .276 & .187 & .363 & .184 & & & & \\
\hline HUM & .594 & .118 & .188 & -.047 & .106 & & & \\
\hline UL & .629 & .204 & .228 & -.175 & .905 & .116 & & \\
\hline FEM & .382 & .122 & .196 & .172 & .658 & .632 & .420 & \\
\hline TIB & .362 & .090 & .170 & .181 & .549 & .622 & .911 & .476 \\
\hline \multicolumn{9}{|l|}{$h^{2} / r_{g} \mathrm{SE}$} \\
\hline & JL & HW & PECT & PELV & HUM & UL & FEM & TIB \\
\hline $\mathrm{JL}$ & .044 & & & & & & & \\
\hline HW & .218 & .044 & & & & & & \\
\hline PECT & .237 & .153 & .057 & & & & & \\
\hline PELV & .259 & .176 & .191 & .054 & & & & \\
\hline HUM & .299 & .201 & .196 & .167 & .027 & & & \\
\hline UL & .295 & .192 & .164 & .160 & .066 & .028 & & \\
\hline FEM & .211 & .158 & .134 & .113 & .127 & .113 & .074 & \\
\hline TIB & .214 & .134 & .108 & .112 & .159 & .130 & .038 & .086 \\
\hline
\end{tabular}


Anolis sagrei (Trunk-ground, Bahamas)

$\begin{array}{lllllllll}\mathbf{G}\left(\times 10^{-3}\right) & & & & & & & \\ & \text { JL } & \text { HW } & \text { PECT } & \text { PELV } & \text { HUM } & \text { UL } & \text { FEM } & \text { TIB } \\ \text { JL } & \mathbf{. 2 9 2} & & & & & & & \\ \text { HW } & \mathbf{. 1 1 2} & \mathbf{. 3 0 2} & & & & & & \\ \text { PECT } & -.002 & \mathbf{. 1 6 6} & \mathbf{. 2 8 6} & & & & & \\ \text { PELV } & -.077 & -.018 & .035 & \mathbf{. 4 6 3} & & & & \\ \text { HUM } & \mathbf{. 1 5 6} & -.073 & .027 & -.109 & \mathbf{. 6 0 3} & & & \\ \text { UL } & .027 & -.142 & -.047 & .082 & \mathbf{. 4 6 2} & \mathbf{. 6 4 6} & & \\ \text { FEM } & \mathbf{. 1 9 2} & -.033 & -.027 & -.011 & \mathbf{. 4 0 9} & \mathbf{. 3 1 5} & \mathbf{. 3 6 8} & \\ \text { TIB } & \mathbf{. 1 7 7} & \mathbf{- . 1 1 1} & -.036 & -.003 & \mathbf{. 5 2 7} & \mathbf{. 5 0 7} & \mathbf{. 4 3 4} & \mathbf{. 6 0 6}\end{array}$

$\mathrm{SE}\left(\times 10^{-3}\right)$

JL HW PECT PELV HUM UL FEM TIB

JL $\quad .023$

$\begin{array}{lll}\mathrm{HW} & .021 & .033\end{array}$

$\begin{array}{llll}\text { PECT } & .024 & .030 \quad .048\end{array}$

$\begin{array}{lllll}\text { PELV } & .050 & .055 & .043 & .073\end{array}$

$\begin{array}{llllll}\text { HUM } & .035 & .050 & .050 & .068 & .092\end{array}$

$\begin{array}{lllllll}\text { UL } & .037 & .044 & .053 & .062 & .080 & .116\end{array}$

$\begin{array}{llllllll}\text { FEM } & .024 & .037 & .042 & .041 & .051 & .051 & .054\end{array}$

$\begin{array}{lllllllll}\text { TIB } & .026 & .044 & .051 & .042 & .058 & .061 & .056 & .073\end{array}$

$\begin{array}{lllllllll}h^{2} / r_{g} & & & & & & & & \\ & \text { JL } & \text { HW } & \text { PECT } & \text { PELV } & \text { HUM } & \text { UL } & \text { FEM } & \text { TIB } \\ \text { JL } & \mathbf{. 4 6 9} & & & & & & & \\ \text { HW } & \mathbf{. 3 7 7} & \mathbf{. 2 6 9} & & & & & & \\ \text { PECT } & -.007 & \mathbf{. 5 6 6} & \mathbf{. 1 2 7} & & & & & \\ \text { PELV } & -.211 & -.049 & .095 & \mathbf{. 1 4 7} & & & & \\ \text { HUM } & \mathbf{. 3 7 2} & -.171 & .065 & -.206 & \mathbf{. 1 3 3} & & & \\ \text { UL } & .063 & -. .321 & -.110 & .149 & \mathbf{. 7 4 0} & \mathbf{. 1 3 0} & & \\ \text { FEM } & \mathbf{. 5 8 5} & -.100 & -.085 & -.027 & \mathbf{. 8 6 9} & \mathbf{. 6 4 7} & \mathbf{. 2 7 0} & \\ \text { TIB } & \mathbf{. 4 2 1} & \mathbf{- . 2 5 9} & -.087 & -.006 & \mathbf{. 8 7 3} & \mathbf{. 8 1 1} & \mathbf{. 9 1 9} & \mathbf{. 4 4 9}\end{array}$

$h^{2} / r_{g} \mathrm{SE}$

JL HW PECT PELV HUM UL FEM TIB

JL $\quad .023$

$\begin{array}{lll}\text { HW } & .059 & .024\end{array}$

$\begin{array}{llll}\text { PECT } & .087 & .083 & .020\end{array}$

$\begin{array}{lllll}\text { PELV } & .134 & .146 & .114 & .021\end{array}$

$\begin{array}{llllll}\text { HUM } & .077 & .116 & .118 & .126 & .019\end{array}$

$\begin{array}{lllllll}\text { UL } & .084 & .097 & .123 & .112 & .069 & .022\end{array}$

$\begin{array}{llllllll}\text { FEM } & .059 & .112 & .131 & .097 & .055 & .083 & .034\end{array}$

$\begin{array}{lllllllll}\text { TIB } & .054 & .097 & .122 & .084 & .048 & .060 & .026 & .041\end{array}$ 
Anolis smaragdinus (Trunk-crown, Bahamas)

\begin{tabular}{|c|c|c|c|c|c|c|c|c|}
\hline \multicolumn{9}{|c|}{$\mathbf{G}\left(\times 10^{-3}\right)$} \\
\hline & $\mathrm{JL}$ & HW & PECT & PELV & HUM & UL & FEM & TIB \\
\hline JL & .348 & & & & & & & \\
\hline HW & .054 & .161 & & & & & & \\
\hline PECT & .251 & .065 & .830 & & & & & \\
\hline PELV & .102 & -.002 & .442 & .560 & & & & \\
\hline HUM & .268 & .151 & .130 & .122 & .395 & & & \\
\hline UL & .238 & .094 & .249 & .300 & .331 & .452 & & \\
\hline FEM & .205 & .061 & .136 & .115 & .285 & .287 & .344 & \\
\hline TIB & .296 & .008 & .221 & .278 & .351 & .423 & .420 & .609 \\
\hline \multicolumn{9}{|c|}{$\mathrm{SE}\left(\times 10^{-3}\right)$} \\
\hline & $\mathrm{JL}$ & HW & PECT & PELV & HUM & UL & FEM & TIB \\
\hline $\mathrm{JL}$ & .129 & & & & & & & \\
\hline HW & .091 & .139 & & & & & & \\
\hline PECT & .171 & .174 & .413 & & & & & \\
\hline PELV & .072 & .068 & .144 & .142 & & & & \\
\hline HUM & .130 & .093 & .163 & .122 & .280 & & & \\
\hline UL & .098 & .134 & .176 & .175 & .181 & .286 & & \\
\hline FEM & .114 & .085 & .184 & .127 & .149 & .149 & .165 & \\
\hline TIB & .125 & .072 & .205 & .141 & .120 & .132 & .158 & .197 \\
\hline \multicolumn{9}{|l|}{$h^{2} / r_{g}$} \\
\hline & JL & HW & PECT & PELV & HUM & UL & FEM & TIB \\
\hline $\mathrm{JL}$ & .455 & & & & & & & \\
\hline HW & .227 & .121 & & & & & & \\
\hline PECT & .468 & .176 & .254 & & & & & \\
\hline PELV & .230 & -.007 & .648 & .251 & & & & \\
\hline HUM & .722 & .600 & .228 & .259 & .100 & & & \\
\hline UL & .601 & .348 & .406 & .596 & .783 & .090 & & \\
\hline FEM & .592 & .257 & .255 & .262 & .773 & .728 & .283 & \\
\hline TIB & .644 & .025 & .311 & .477 & .717 & .806 & .919 & .454 \\
\hline \multicolumn{9}{|l|}{$h^{2} / r_{g} \mathrm{SE}$} \\
\hline & $\mathrm{JL}$ & HW & PECT & PELV & HUM & UL & FEM & TIB \\
\hline $\mathrm{JL}$ & .137 & & & & & & & \\
\hline HW & .353 & .101 & & & & & & \\
\hline PECT & .248 & .450 & .116 & & & & & \\
\hline PELV & .151 & .254 & .179 & .053 & & & & \\
\hline HUM & .298 & .421 & .302 & .261 & .068 & & & \\
\hline UL & .235 & .481 & .296 & .306 & .290 & .055 & & \\
\hline FEM & .207 & .348 & .337 & .274 & .307 & .311 & .122 & \\
\hline TIB & .154 & .223 & .279 & .205 & .269 & .243 & .094 & .118 \\
\hline
\end{tabular}


Table A2: Random skewers correlations $\left(r_{\mathrm{RS}}\right)$ for each species pair. Point estimates, REMLMVN estimates, and 95\% confidence intervals are shown. Point estimates occasionally lie outside the REML-MVN confidence interval because incorporating estimation error from two $\mathbf{G}$ matrices lead to negatively skewed distributions.

$\begin{array}{llrrrr}\text { species } 1 & \text { Species } 2 & r_{\text {RS }} & \text { REML-MVN } r_{\text {RS }} & 2.5 \% & 97.5 \% \\ \text { CRIS } & \text { EVER } & .89 & .86 & .80 & .91 \\ \text { CRIS } & \text { GRAH } & .84 & .74 & .59 & .84 \\ \text { CRIS } & \text { LINE } & .78 & .70 & .55 & .81 \\ \text { CRIS } & \text { PULC } & .87 & .81 & .71 & .88 \\ \text { CRIS } & \text { SAGR } & .88 & .85 & .79 & .89 \\ \text { CRIS } & \text { SMAR } & .81 & .66 & .43 & .82 \\ \text { EVER } & \text { GRAH } & .83 & .74 & .60 & .84 \\ \text { EVER } & \text { LINE } & .81 & .73 & .55 & .83 \\ \text { EVER } & \text { PULC } & .90 & .84 & .74 & .91 \\ \text { EVER } & \text { SAGR } & .84 & .81 & .75 & .87 \\ \text { EVER } & \text { SMAR } & .82 & .68 & .47 & .81 \\ \text { GRAH } & \text { LINE } & .85 & .70 & .52 & .83 \\ \text { GRAH } & \text { PULC } & .88 & .75 & .60 & .86 \\ \text { GRAH } & \text { SAGR } & .87 & .76 & .62 & .86 \\ \text { GRAH } & \text { SMAR } & .79 & .61 & .38 & .77 \\ \text { LINE } & \text { PULC } & .92 & .79 & .64 & .89 \\ \text { LINE } & \text { SAGR } & .76 & .67 & .52 & .78 \\ \text { LINE } & \text { SMAR } & .81 & .63 & .39 & .79 \\ \text { PULC } & \text { SAGR } & .82 & .76 & .66 & .83 \\ \text { PULC } & \text { SMAR } & .84 & .66 & .44 & .82 \\ \text { SAGR } & \text { SMAR } & .76 & .63 & .42 & .77\end{array}$


Table A3: Estimates of phylogenetic signal (Blomberg's $K$ ) for all genetic variances and correlations. Point estimates, REML-MVN estimates, and 95\% confidence intervals are shown. All estimates of $K$ were significantly different from 0 and indistinguishable from 1 .

\begin{tabular}{lrrrr}
\multicolumn{2}{l}{ Variances } & & & \\
Trait & \multicolumn{1}{l}{$K$} & REML-MVN $K$ & $2.5 \%$ & $97.5 \%$ \\
JL & .81 & .86 & .65 & 1.11 \\
HW & .69 & .77 & .61 & 1.05 \\
PECT & 1.16 & 1.13 & .79 & 1.53 \\
PELV & .90 & .90 & .69 & 1.18 \\
RAD & .87 & .90 & .69 & 1.20 \\
UL & 1.15 & 1.03 & .77 & 1.31 \\
FEM & .99 & 1.00 & .83 & 1.31 \\
TIB & .90 & .91 & .77 & 1.13
\end{tabular}

Correlations

\begin{tabular}{llrrrr} 
Trait 1 & Trait 2 & \multicolumn{1}{c}{$K$} & REML-MVN $K$ & $2.5 \%$ & $97.5 \%$ \\
JL & HW & .92 & .96 & .74 & 1.26 \\
JL & PECT & .71 & .76 & .64 & 1.00 \\
JL & PELV & .88 & .91 & .67 & 1.25 \\
JL & HUM & .91 & .93 & .69 & 1.20 \\
JL & UL & .78 & .84 & .67 & 1.12 \\
JL & FEM & 1.04 & 1.00 & .73 & 1.32 \\
JL & TIB & .95 & .92 & .73 & 1.17 \\
HW & PECT & .97 & .97 & .74 & 1.19 \\
HW & PELV & 1.04 & 1.01 & .71 & 1.39 \\
HW & HUM & 1.04 & 1.01 & .82 & 1.20 \\
HW & UL & .97 & .99 & .84 & 1.14 \\
HW & FEM & .91 & .97 & .78 & 1.20 \\
HW & TIB & .97 & .97 & .82 & 1.16 \\
PECT & PELV & 1.02 & .98 & .74 & 1.30 \\
PECT & HUM & .85 & .92 & .65 & 1.30 \\
PECT & UL & .92 & .94 & .71 & 1.19 \\
PECT & FEM & .91 & .95 & .77 & 1.18 \\
PECT & TIB & 1.02 & 1.01 & .80 & 1.24 \\
PELV & HUM & .90 & .92 & .75 & 1.15 \\
PELV & UL & 1.03 & 1.00 & .77 & 1.19 \\
PELV & FEM & .81 & .89 & .71 & 1.11 \\
PELV & TIB & .93 & .94 & .72 & 1.18 \\
HUM & UL & .90 & .99 & .76 & 1.22 \\
HUM & FEM & .78 & .92 & .72 & 1.17 \\
HUM & TIB & .76 & .87 & .71 & 1.13 \\
UL & FEM & .87 & .98 & .71 & 1.31 \\
UL & TIB & .80 & .91 & .71 & 1.17 \\
FEM & TIB & .79 & .93 & .72 & 1.14 \\
& & & & &
\end{tabular}


Table A4: Ecomorph effects given as evolutionary correlations $\left(r_{\mathrm{e}}\right)$ for all genetic variances and correlations. A positive value indicates that trunk-ground species have a higher value than trunkcrown species. Point estimates, REML-MVN estimates, and 95\% confidence intervals are shown. Significant values are indicated with boldface.

\begin{tabular}{lrrrr}
\multicolumn{4}{c}{ Variances } \\
Trait & $r_{e}$ & REML-MVN $r_{e}$ & $2.5 \%$ & $97.5 \%$ \\
JL & .62 & .48 & -.17 & .88 \\
HW & .52 & .39 & -.26 & .84 \\
PECT & .23 & .19 & -.27 & .56 \\
PELV & .03 & -.04 & -.85 & .58 \\
RAD & .44 & .36 & -.24 & .78 \\
UL & .09 & .08 & -.59 & .70 \\
FEM & .01 & -.02 & -.49 & .34 \\
TIB & -.35 & -.34 & -.65 & .02
\end{tabular}

\section{Correlations}

$\begin{array}{llrrrr}\text { Trait 1 } & \text { Trait 2 } & r_{e} & \text { REML-MVN } r_{e} & 2.5 \% & 97.5 \% \\ \text { JL } & \text { HW } & .28 & .25 & -.13 & .52 \\ \text { JL } & \text { PECT } & -.23 & -.21 & -.60 & .22 \\ \text { JL } & \text { PELV } & -.56 & -.49 & -.84 & -.03 \\ \text { JL } & \text { HUM } & .09 & .07 & -.64 & .79 \\ \text { JL } & \text { UL } & -.20 & -.17 & -.64 & .32 \\ \text { JL } & \text { FEM } & . \mathbf{6 3} & .55 & .05 & .90 \\ \text { JL } & \text { TIB } & .49 & .43 & -.06 & .84 \\ \text { HW } & \text { PECT } & .24 & .11 & -.73 & .57 \\ \text { HW } & \text { PELV } & .03 & .02 & -.60 & .58 \\ \text { HW } & \text { HUM } & -.13 & -.09 & -.63 & .52 \\ \text { HW } & \text { UL } & -.01 & .00 & -.47 & .50 \\ \text { HW } & \text { FEM } & .08 & .04 & -.68 & .64 \\ \text { HW } & \text { TIB } & -.07 & -.09 & -.75 & .48 \\ \text { PECT } & \text { PELV } & -.37 & -.27 & -.79 & .36 \\ \text { PECT } & \text { HUM } & -.55 & -.35 & -.86 & .39 \\ \text { PECT } & \text { UL } & -.44 & -.33 & -.85 & .35 \\ \text { PECT } & \text { FEM } & -.11 & -.10 & -.70 & .42 \\ \text { PECT } & \text { TIB } & -.24 & -.21 & -.68 & .28 \\ \text { PELV } & \text { HUM } & -.96 & -.78 & -.98 & -.32 \\ \text { PELV } & \text { UL } & -.68 & -.58 & -.89 & -.06 \\ \text { PELV } & \text { FEM } & -.82 & -.62 & -.97 & -.01 \\ \text { PELV } & \text { TIB } & -.87 & -.74 & -.97 & -.25 \\ \text { HUM } & \text { UL } & -.16 & -.14 & -.82 & .46 \\ \text { HUM } & \text { FEM } & -.37 & -.21 & -.72 & .59 \\ \text { HUM } & \text { TIB } & -.33 & -.21 & -.70 & .59 \\ \text { UL } & \text { FEM } & -.64 & -.35 & -.86 & .41 \\ \text { UL } & \text { TIB } & -.58 & -.37 & -.82 & .45 \\ \text { FEM } & \text { TIB } & -.65 & -.45 & -.94 & .20\end{array}$

